\title{
Pharmacological and physiological characterization of the tremulous jaw movement model of parkinsonian tremor: Potential insights into the pathophysiology of tremor
}

\author{
Lyndsey E. Collins-Praino ', Nicholas E. Paul' ', Kristen L. Rychalsky', James R. Hinman', James J. Chrobak', \\ Patrick B. Senatus ${ }^{2}$ and John D. Salamone ${ }^{1 *}$
}

Behavioral Neuroscience Division, Department of Psychology, University of Connecticut, Storrs, CT, USA

2 Department of Surgery, University of Connecticut Health Center, Farmington, CT, USA

\author{
Edited by: \\ Elizabeth Abercrombie, Rutgers- \\ Newark: The State University of New \\ Jersey, USA

\section{Reviewed by:} \\ Gregor Rainer, University of Fribourg, \\ Switzerland \\ Constance Hammond, Université de la \\ Méditerrannée, France \\ *Correspondence: \\ John D. Salamone, Division of \\ Behavioral Neuroscience, Department \\ of Psychology, University of \\ Connecticut, Storrs, CT 06269-1020, \\ USA. \\ e-mail: john.salamone@uconn.edu
}

Tremor is a cardinal symptom of parkinsonism, occurring early on in the disease course and affecting more than $70 \%$ of patients. Parkinsonian resting tremor occurs in a frequency range of 3-7 Hz and can be resistant to available pharmacotherapy. Despite its prevalence, and the significant decrease in quality of life associated with it, the pathophysiology of parkinsonian tremor is poorly understood. The tremulous jaw movement (TJM) model is an extensively validated rodent model of tremor. TJMs are induced by conditions that also lead to parkinsonism in humans (i.e., striatal DA depletion, DA antagonism, and cholinomimetic activity) and reversed by several antiparkinsonian drugs (i.e., DA precursors, DA agonists, anticholinergics, and adenosine $\mathrm{A}_{2 \mathrm{~A}}$ antagonists). TJMs occur in the same 3-7 $\mathrm{Hz}$ frequency range seen in parkinsonian resting tremor, a range distinct from that of dyskinesia $(1-2 \mathrm{~Hz})$, and postural tremor $(8-14 \mathrm{~Hz})$. Overall, these drug-induced TJMs share many characteristics with human parkinsonian tremor, but do not closely resemble tardive dyskinesia. The current review discusses recent advances in the validation of the TJM model, and illustrates how this model is being used to develop novel therapeutic strategies, both surgical and pharmacological, for the treatment of parkinsonian resting tremor.

Keywords: dopamine, adenosine A2A, acetylcholine, muscarinic, basal ganglia, caudate putamen, neostriatum, subthalamic nucleus

\section{PARKINSONIAN RESTING TREMOR}

Idiopathic Parkinson's disease is just one member of a broader family of motor disorders known as parkinsonism (Alvarez et al., 2007), a group that also includes encephalitic, pugilistic, and drug-induced parkinsonism. Regardless of subtype, all forms of parkinsonism share in common four core symptoms: bradykinesia, postural instability, rigidity, and tremor (Hoehn and Yahr, 1967). Tremor, defined as "a rhythmic and involuntary oscillation of a body part, caused by reciprocal innervations of a muscle, which leads to repetitive, stereotyped contractions with regular frequency and amplitude," is sometimes considered to be the cardinal symptom of parkinsonism (Deuschl et al., 2000; Mansur et al., 2007). This tremor, present predominantly at rest, appears early on in the disease course and causes a significant amount of life distress (Mansur et al., 2007). It presents in up to $75 \%$ of individuals with $\mathrm{PD}$, and has been shown to occur in a frequency range of 3-7 Hz, a range distinct from that seen in dyskinesias $(1-2 \mathrm{~Hz})$, essential tremor $(8 \mathrm{~Hz})$, and postural tremors (8-12 Hz; Findley et al., 1981; Findley and Capildeo, 1984; Marsden, 1984; Elbe and Koller, 1990; Hunker and Abbs, 1990; Deuschl et al., 1996, 2000; Spieker et al., 1997).

Usually beginning unilaterally in the distal segments of the extremities, parkinsonian tremor frequently spreads bilaterally, often affecting both upper and lower limbs, as well as facial muscles, as the disease progresses (Adams and Victor, 1993; Koster et al., 1997; Salamone et al., 1998; Deuschl et al., 2000; Morrison et al., 2008). While the most common form of parkinsonian resting tremor in humans is a "pill rolling" tremor of the hands, tremulous "up-and-down" movements of the jaw in parkinsonian patients have also been well documented (Barbeau, 1986; Selby, 1986; Young, 1986; Hunker and Abbs, 1990; Adams and Victor, 1993; Ben-Pazi et al., 2001; Schneider et al., 2006; Sheffield and Jankovic, 2007; Leventoglu and Baysal, 2008; Jankovic, 2009). Oral tremor also is induced by long-term administration of DA antagonists, a condition known as "rabbit syndrome" and defined as "rhythmic jaw tremor" (Weiss et al., 1980). This type of tremor is alleviated by common antiparkinsonian drugs, but exacerbated by cholinomimetic administration (Sovner and Dimascio, 1977; Weiss et al., 1980; Yassa and Lal, 1986). Thus, it is considered to be a form of drug-induced parkinsonian tremor (Sovner and Dimascio, 1977; Weiss et al., 1980; Tarsy, 1983).

The neural network thought to underlie parkinsonian tremor is complex, consisting of changes to the open and closed loop connections between neocortex, basal ganglia, and thalamus. According to current models of basal ganglia function, reductions of the DA input from substantia nigra pars compacta (particularly from the retrorubral area $\mathrm{A} 8$ portion of the $\mathrm{SNc}$ in tremor-dominant $\mathrm{PD}$ ) to the striatum leads to an increase in output from the subthalamic nucleus (STN), a nucleus consisting of neurons and circuits that are 
particularly correlated with tremor (Reck et al., 2009). This, in turn, produces an overstimulation of GABAergic neurons in substantia nigra pars reticulata ( $\mathrm{SNr}$ ) and globus pallidus internal (GPi), and a subsequent inhibition of the ventral lateral and ventral anterior nuclei of the thalamus, leading ultimately to the reduced output of the sensorimotor cortex and the motor impairments observed in parkinsonism. Most recently, hypotheses of parkinsonism have focused not just on these changes in firing rates, but also on alterations in firing patterns (see Obeso et al., 2000, 2008; Bevan et al., 2002; Brown, 2003 for review). Specifically, increases in the activity of subthalamic and internal globus pallidus neurons are thought to cause these nuclei to enter a regime of rhythmic firing, resulting in an excessive synchrony (particularly in the Beta band; Bergman et al., 1998; Obeso et al., 2000, 2008; Brown et al., 2001; Levy et al., 2002). This excessive synchrony may be particularly important for the generation and maintenance of parkinsonian tremor.

The neurochemical cascade thought to underlie parkinsonian tremor is similarly multifaceted, with multiple neurotransmitters, including GABA, serotonin, adenosine, and acetylcholine (ACh), interacting with DA in the regulation of basal ganglia motor functions related to parkinsonism (Hornykiewicz, 1972, 1973; DeLong, 1990; Young and Penney, 1993; McSwain and Forman, 1995; Finn et al., 1997b; Hauber et al., 1998; Salamone et al., 1998; Mayorga et al., 1999a; Wichmann et al., 2001; Trevitt et al., 2002; Carlson et al., 2003a,b; Ishiwari et al., 2004; Obeso et al., 2008; Vanover et al., 2008). Interestingly, these other neurotransmitters offer additional avenues for therapeutic intervention. In addition to DAergic treatments for parkinsonism, muscarinic antagonists often are used as antiparkinsonian agents, and they have been shown in clinical studies to suppress tremor (McEvoy, 1983; Schrag et al., 1999; Milanov, 2001; Koller, 2002). More recently, antagonists of adenosine $A_{2 A}$ receptors have been shown to produce antitremor effects in animal models (Correa et al., 2004; Salamone et al., 2008a,b) and in human patients with Parkinson's disease (Bara-Jimenez et al., 2003; Pinna, 2009).

The study of parkinsonian tremor has proven to be something of an enigma in the field. Although tremor is considered to be the most specific marker of parkinsonism, with estimates of 95\% probability that the presence of classical resting tremor indicates idiopathic PD, tremor severity has not been shown to parallel disease progression (Deuschl et al., 2000). Additionally, the system dynamics of parkinsonian tremor have shown that, despite the nearly uniform frequencies associated with tremor-related oscillations (i.e., 3-7 Hz; Hunker and Abbs, 1990), these oscillations occur independently of one another, with electromyographic (EMG) activity of tremor in one limb being uncorrelated to the EMG activity of another limb exhibiting tremor (O'Suilleabhain and Matsumoto, 1998; Hurtado et al., 2000, 2004; Raethjen et al., 2000, 2009; Ben-Pazi et al., 2001). Even within the tremor circuitry itself, tremors have not been shown to be tightly correlated with tremor-related neural activity in the nuclei of the basal ganglia and thalamus: tremor-related neural activity may wax and wane while limb tremor persists; conversely, tremor-related oscillations may exist in the neurocircuitry while no limb tremor is apparent (Hurtado et al., 2004). These seemingly paradoxical findings have led to a variety of questions about the pathophysiology underlying tremorogenesis in parkinsonism. Yet despite these lingering questions, relatively few clinical studies have specifically emphasized the pharmacology of tremor (e.g., Schrag et al., 2002; Navan et al., 2003, 2005; Sung et al., 2008; Binder et al., 2009) and there is considerable uncertainty about the neurochemical mechanisms that underlie the pathophysiology of parkinsonian tremor (Wilms et al., 1999; Deuschl et al., 2000, 2001; Bergman and Deuschl, 2002; Sung et al., 2008). While parkinsonian tremor seems to result from oscillating activity in the central nervous system (and not due to reflexes in the periphery; see Hunker and Abbs, 1990 for review), it appears to be generated by multiple oscillators, and it is unclear where these oscillators are located (though the basal ganglia loops are a likely candidate, oscillators in the thalamus have also been proposed) or by what mechanism these oscillators produce tremor (O'Suilleabhain and Matsumoto, 1998; Deuschl et al., 2000). Given the uncertainty surrounding this cardinal symptom of parkinsonism, studies employing animal models of parkinsonian resting tremor are imperative (Muthuraman et al., 2008). Basic research using animal models of drug-induced tremor enables researchers to investigate the neurochemical mechanisms that regulate tremor and to study the development of oscillatory patterns of activity in the brain that are thought to underlie tremorogenesis. Eventually, this research could lead to the development of novel treatments.

\section{THE TREMULOUS JAW MOVEMENT MODEL IN RODENTS: DEVELOPMENT AND VALIDATION}

While a variety of animal models of parkinsonian tremor exist, most of these are models of postural or action tremors, and not of resting tremor (see Wilms et al., 1999). Although a few models of resting tremor have been produced, these have mainly been in primates and have involved the destruction of multiple nuclei or pathways, a paradigm that is expensive and impractical for most preclinical pharmaceutical testing (Wilms et al., 1999). The tremulous jaw movement (TJM) model may provide a resolution for many of these difficulties. TJMs, defined as rapid vertical deflections of the lower jaw that are not directed at any stimulus, are a rodent model of parkinsonian resting tremor (for reviews, see Salamone et al., 1998, 2001, 2005; see also Rodriguez Diaz et al., 2001; Cenci et al., 2002). TJMs generally occur in phasic bursts of repetitive jaw movement activity, with multiple movements within each burst. Willner (1990) cautions that animal models should undergo an evaluation for their validity using criteria similar to those used in the rigorous validation of psychological tests. Thus, a great deal of effort has been expended in the analysis of the pharmacological, temporal, and anatomical characteristics of the TJM model in order to evaluate whether these tremulous movements in rats are sufficiently similar to human parkinsonian tremor to allow for their validation as an animal model of tremor. TJMs have been shown to possess many of the neurochemical, anatomical, and pharmacological characteristics of parkinsonism, and thus meet a reasonable set of validation criteria for use as an animal model of parkinsonian tremor (Salamone et al., 1998; Cenci et al., 2002). Animal models in psychopharmacology are evaluated for their validity based upon a number of criteria (Willner, 1990). These including face validity (the phenomenological similarity between the model and the disorder, including etiology and symptomatology), construct validity (the degree of similarity between the identified variable (e.g., tremor), and the behavior being studied in the model), and predictive validity (primarily, the positive response to therapeutic 
drugs). As described below, the TJM model of parkinsonism is one of the few models of experimental tremor that meets these validation criteria.

\section{VALIDATION OF THE TREMULOUS JAW MOVEMENT MODEL: TJMS ARE INDUCED BY THE SAME NEUROCHEMICAL AND PHARMACOLOGICAL CONDITIONS THAT LEAD TO PARKINSONISM IN HUMANS}

Tremulous jaw movements are induced by a number of conditions that parallel the neurochemistry of idiopathic and druginduced parkinsonism. For example, several DAergic conditions that are associated with parkinsonism in humans have been shown to induce TJMs (Table 1). Depletions of striatal dopamine by the neurotoxic agent 6-OHDA (Jicha and Salamone, 1991; Finn et al., 1997b; Rodriguez-Diaz et al., 2001) or acute administration of reserpine (Baskin and Salamone, 1993; Steinpreis and Salamone, 1993; Salamone and Baskin, 1996; Salamone et al., 2008b) have been shown to induce TJM activity in rats. Several studies have demonstrated that TJMs are also induced by acute or sub-chronic administration of "typical" antipsychotic drugs that act as DA antagonists (Glassman and Glassman, 1980; Rupniak et al., 1985, 1986; Jicha and Salamone, 1991; Steinpreis and Salamone, 1993; Steinpreis et al., 1993; Egan et al., 1996; Trevitt et al., 1998; Wisniecki et al., 2003; Ishiwari et al., 2005; Betz et al., 2007, 2009; Collins et al., 2010a). In contrast, "atypical” antipsychotic drugs, such as clozapine, olanzapine, and quetiapine, which are less likely to induce motor side effects in humans, do not induce TJMs (Trevitt et al., 1998, 1999; Betz et al., 2005, 2009).

Cholinomimetic drugs acting on central muscarinic receptors, which can produce or exacerbate parkinsonian symptoms in humans (Duvoisin, 1967; Aquilonius, 1980; Ott and Lannon, 1992; Kao et al., 1993; Song et al., 2008), also produce robust bursts of TJM activity in rats (Rupniak et al., 1983, 1985; Salamone et al., 1986, 2005; Table 1). Muscarinic agonists, such as pilocarpine, have been repeatedly demonstrated to induce TJMs (Rupniak et al., 1983, 1985; Salamone et al., 1986, 1990; Stewart et al., 1987, 1988; Baskin et al., 1994; Finn et al., 1997a,b; Collins et al., 2010a). Similar findings have been reported with the administration of various anticholinesterases, including physostigmine and tacrine (Kelley et al., 1989; Mayorga et al., 1997; Simola et al., 2004; Tronci et al., 2007; Kasture et al., 2009; Pinna et al., 2010). Most recently, galantamine, a "new generation" anticholinesterase, was demonstrated to induce TJMs (Collins et al., 2011; Figure 1). This is consistent with data from clinical patient populations, which suggest that the "new generation" anticholinesterases donepezil, rivastigmine, and galantamine also induce tremor (Bourke and Drukenbrod, 1998; Shea et al., 1998; Arai, 2000; Aarsland et al., 2003; Gurevich et al., 2006; McCain et al., 2007; Litvinenko et al., 2008; Song et al., 2008). Donepezil, for example, has been reported to induce jaw tremor as a side effect (Song et al., 2008). Given the increasing numbers of people receiving anticholinesterases for the treatment of Alzheimer's disease, this is particularly concerning, and suggests that a new population of people may be at risk for developing drug-induced tremor. These observations indicate that research on the pathogenesis of tremor needs to include anticholinesterase-induced tremor as well as DAergic conditions.

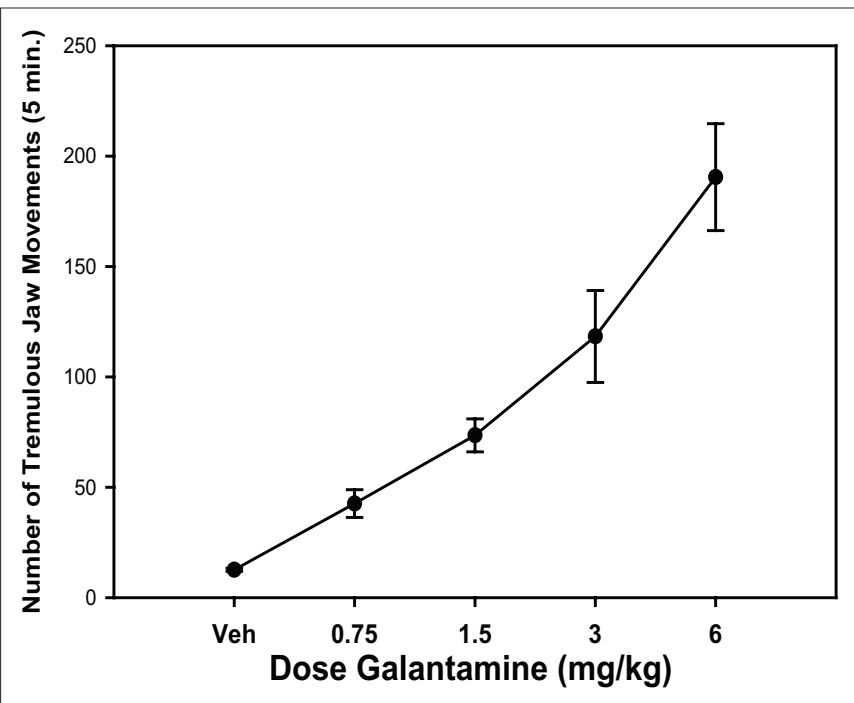

FIGURE 1 | Effects of different IP doses of the anticholinesterase galantamine on tremulous jaw movements (Collins et al., 2011). Mean $( \pm$ SEM) number of jaw movements (per $5 \mathrm{~min}$ ) in rats $(n=8)$ treated with either saline vehicle (Veh) or galantamine. Using a within-groups design, all rats received all drug treatments in a randomly varied order (one treatment per week). Rats were observed in three 5-min periods 10-25 min after injection. Repeated measures ANOVA revealed that galantamine produced a significant increase in tremulous jaw movement activity $[F(4,28)=25.8 ; p<0.001]$. * Significant difference from vehicle control $(p<0.05)$.

\section{VALIDATION OF THE TREMULOUS JAW MOVEMENT MODEL: TJMS OCCUR IN THE SAME LOCAL FREQUENCY RANGE AS PARKINSONIAN TREMOR}

Parkinsonian resting tremor in humans is generally reported to occur within a peak frequency range of 3-7 Hz (Adams and Victor, 1993; Staude et al., 1995). This range is distinct from that seen in dyskinesias $(1-2 \mathrm{~Hz})$, essential tremor $(8 \mathrm{~Hz})$, and postural tremors (8-12 Hz) (Findley et al., 1981; Findley and Gresty 1981, 1988; Findley and Capildeo, 1984; Marsden, 1984; Findley, 1988; Elbe and Koller, 1990; Hunker and Abbs, 1990; Deuschl et al., 1996, 2000; Spieker et al., 1997). Strikingly, the tremulous oral movements that are induced by interference with DA transmission and by cholinomimetics have also been found to occur within the 3 to 7-Hz range, consistent with the frequency of parkinsonian resting tremor in humans (See and Chapman, 1991; Salamone and Baskin, 1996; Finn et al., 1997b; Mayorga et al., 1997; Cousins et al., 1998; Salamone et al., 1998; Ishiwari et al., 2005; Collins et al., 2010a; Galtieri et al., 2010).

Studies employing slow-motion videotaping methods have demonstrated that the majority of TJMs induced either by interference with striatal dopamine (either through DA depletion or antagonism; Salamone and Baskin, 1996; Finn et al., 1997b; Ishiwari et al., 2005) or cholinomimetic stimulation (Finn et al., 1997b; Mayorga et al., 1997; Collins et al., 2011) occur in "bursts" with a local frequency range of $3-7 \mathrm{~Hz}$ (based on an analysis of the inter-movement time, whereby local frequency was equal to the inverse of the inter-movement time). EMG recording methods also have been used to characterize the local frequency of TJMs. Cousins et al. (1998) found that the lateral temporalis muscle is the 
jaw closing muscle most strongly correlated with tacrine-induced TJMs in rats; examination of $1 \mathrm{~s}$ raw EMG traces demonstrated that the local frequency of these TJMs was in the 3 to $7-\mathrm{Hz}$ frequency (Cousins et al., 1998). Furthermore, this study indicated that the variability in the jaw movement frequency distribution obtained was comparable to the variability in tremor frequencies shown by parkinsonian patients (see Staude et al., 1995). A more recent study demonstrated that the frequency range of TJMs induced by the muscarinic agonist pilocarpine were in the 3 to $7-\mathrm{Hz}$ frequency range after both a high $(4.0 \mathrm{mg} / \mathrm{kg})$ and low $(0.5 \mathrm{mg} / \mathrm{kg})$ dose (Collins et al., 2010a).

Currently, improvements in the frequency characterization of TJMs are being conducted using time series analysis of EMG data. Since the physiological events underlying tremor can be considered as a continuously varying waveform, the use of these continuous time series techniques (as opposed to discrete stochastic point process techniques) is appropriate for the analysis of the EMG data obtained from rats displaying TJMs (Halliday et al., 1995). More specifically, because tremor has been described as a second order linear stochastic process, spectral analysis techniques based on the Fourier transform can be used (Timmer et al., 1998a,b). The employment of these techniques provides for a systematic, quantitative temporal analysis of EMG data recorded during drug-induced TJMs. A recent study employed these techniques to perform a frequency analysis of the jaw movements induced by both DA antagonism and cholinomimetic administration (Collins et al., 2010c). Rats were implanted with tungsten wire electrodes bilaterally in the lateral temporalis muscle. Following a sufficient recovery period, rats received either an acute injection of the muscarinic agonist pilocarpine, the anticholinesterase galanthamine, or a sub-chronic injection of the DA D2 antagonist pimozide. Rats were then connected to a Cheetah 16 Neuralynx recording system (Neuralynx, Bozeman, MT, USA) via a mutliwire cable and recordings of EMG activity during TJM observation were performed. Representative traces were examined using the Neuraview program (Neuralynx, Bozeman, MT, USA) to identify appropriate epochs of tremor and non-tremor activity and then imported into Matlab 7.4 (Mathworks Inc., Natick, MA, USA). A spectrum of each epoch was then calculated using the multi-taper spectral estimation method. Spectral analysis revealed that, during periods of tremor activity, a distinct peak was consistently present between 4 and $7 \mathrm{~Hz}$. This was true for tremor activity induced by both DA antagonism and cholinomimetic administration. Conversely, during periods of quiescence (i.e., when no tremor activity was occurring in the jaw), no distinct peak was present in the spectral analysis. Example traces and spectral analyses are presented in Figure 2. These results with time series analysis demonstrate that drug-induced TJMs are accompanied by EMG activity that is occurring in the parkinsonian tremor frequency range, and serve to provide further validation of the TJM model of parkinsonian resting tremor.

\section{VALIDATION OF THE TREMULOUS JAW MOVEMENT MODEL: TJMS ARE REVERSED BY WELL CHARACTERIZED AND PUTATIVE ANTIPARKINSONIAN DRUGS}

In addition to being produced by many of the same neurochemical conditions that induce parkinsonism in humans, TJMs in rats also can also be reduced by both clinically utilized and putative

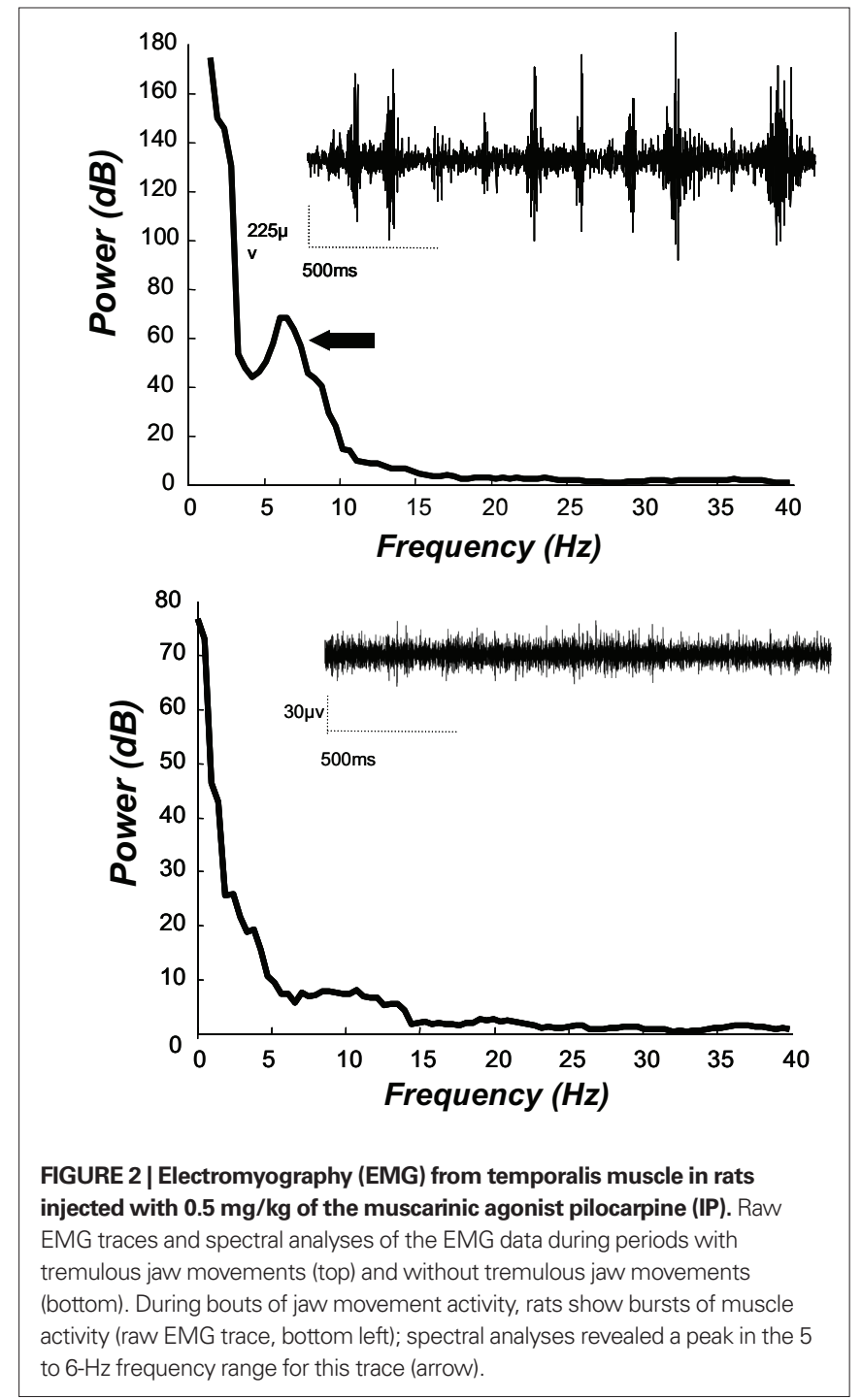

antiparkinsonian drugs from many drug classes (Table 2). Administration of L-DOPA, currently the gold standard for the treatment of parkinsonian motor impairment, led to a significant reduction of TJMs (Cousins and Salamone, 1996; Cousins et al., 1997). Similarly, several DA agonists, including apomorphine, pergolide, bromocriptine, ropinirole and CY 208-243, have been shown to reduce TJMs (Baskin and Salamone, 1993; Cousins et al., 1997; Salamone et al., 2005). The potency of DAergic drugs for suppressing TJMs is highly correlated with the clinical potency of these drugs for reducing parkinsonian tremor in humans (Salamone et al., 2005). For example, the weak partial D1 agonist SKF 38393, which is not antiparkinsonian in humans or primates (Braun et al., 1987; Boyce et al., 1990; Close et al., 1990), did not decrease cholinomimeticinduced jaw movements (Cousins et al., 1997). Conversely, the full DA D1 receptor agonists SKF 82958 and dihydrexidine, which have been shown to have antiparkinsonian actions in MPTP-treated primates (Taylor et al., 1991; Akai et al., 1995a,b; Gnanalingham et al., 1995), are capable of producing a robust suppression of cholinomimetic-induced TJMs (Mayorga et al., 1999a). 
Antiparkinsonian anticholinergics, such as the muscarinic antagonists benztropine, scopolamine, and atropine, also reliably suppress TJM activity (Rupniak et al., 1983; Salamone et al., 1986, 1990; Steinpreis et al., 1993; Salamone and Baskin, 1996; Cousins et al., 1997; Mayorga et al., 1997; Betz et al., 2007, 2009; Table 2). Taken together with studies showing that cholinomimetics can induce TJMs, these findings reinforce the idea that the striatal DA and ACh systems interact in a complex way to regulate motor function and dysfunction (Aquilonius, 1980; Zigmond et al., 1987; Olianas et al., 1996; Salamone et al., 1998, 2001; Olianas and Onali, 1999; Calabresi et al., 2000, 2006; Pisani et al., 2003, 2007; Zhou et al., 2003; Morris et al., 2004; Cragg, 2006; Threlfell et al., 2010). The striatum contains large aspiny cholinergic neurons, and is rich in muscarinic receptors, with M1 and M4 subtypes being the predominant postsynaptic receptors (Hersch et al., 1994; Santiago and Potter, 2001). The M4 subtype of muscarinic receptor in particular has been implicated in the regulation of TJM activity (Mayorga et al., 1999c; Salamone et al., 2001; Betz et al., 2007, 2009).

Most recently, the ability of adenosine $\mathrm{A}_{2 \mathrm{~A}}$ antagonists to reverse TJMs has been extensively studied (Table 2 ). Adenosine $\mathrm{A}_{2 \mathrm{~A}}$ receptors are highly expressed in neostriatum, and $\mathrm{A}_{2 \mathrm{~A}}$ antagonists exert motor effects in rodents and primates that are consistent with antiparkinsonian actions (Ferré et al., 1997, 2004; Rosin et al., 1998; Chen et al., 2001; Morelli and Pinna, 2001; Morelli et al., 2007; Salamone et al., 2008b; Collins et al., 2010a,b). Human clinical reports have indicated that the adenosine $\mathrm{A}_{2 \mathrm{~A}}$ antagonists istradefylline (KW 6002), preladenant (SCH 420814), ST-1535, and BIIB014 significantly improve motor deficits, reduce OFF time, and increase ON time in parkinsonian patients, suggesting that members of this drug class may be efficacious as antiparkinsonian agents (Hauser et al., 2003, 2008; Jenner, 2005; LeWitt et al., 2008; Stacy et al., 2008; Gillespie et al., 2009; Pinna, 2009; Factor et al., 2010; Fernandez et al., 2010; Mizuno et al., 2010; Salamone, 2010; Knebel et al., 2011). The adenosine $A_{2 \mathrm{~A}}$ antagonists KF 17837, istradefylline, SCH 58261, ST 1535, ANR94, AA47070, MSX-3, and MSX-4 have all been shown to significantly reverse the TJMs induced by DA depletion, DA antagonism, and cholinomimetic administration (Correa et al., 2004; Simola et al., 2004; Tronci et al., 2007; Salamone et al., 2008a; Betz et al., 2009; Collins et al., 2010a; Pinna et al., 2010; Collins et al., 2011; CollinsPraino et al., 2011b). The ability of TJMs to be reversed by several classes of commonly used as well as experimental antiparkinsonian drugs provides support for the predictive validity of the TJM model as a rodent model of parkinsonian tremor.

\section{VALIDATION OF THE TREMULOUS JAW MOVEMENT MODEL: ANATOMICAL CHARACTERISTICS OF THE TJMS IN RATS ARE SIMILAR TO THOSE OF HUMAN PARKINSONIAN TREMOR}

Multiple studies have demonstrated that TJMs induced by interference with DA transmission and by cholinomimetic administration are dependent upon striatal mechanisms, particularly upon the ventrolateral striatum (VLS). The VLS, thought to be a rodent homolog of the primate ventral putamen, is somatotopically organized (Pisa, 1988; Jicha and Salamone, 1991; Salamone et al., 1993a,b) and receives input from sensory and motor cortices related to head, orofacial, and forepaw areas (McGeorge and Faull, 1989; Salamone et al., 1998). Since the VLS is considered to be the homolog of the primate ventral putamen, it is interesting to note that the putamen is the striatal subregion within which DA depletions are most highly correlated with the presence of tremor in human parkinsonian patients (Bernheimer et al., 1973). Overall, the VLS is considered to be a critical striatal subregion at which DA, ACh, and adenosine receptor mechanisms interact to regulate TJMs (Salamone et al., 1998, 2008b; see VLS section in Figure 3).

Depletions of DA in the VLS by local injections of 6-OHDA were shown to induce TJMs, while injections in other striatal regions were ineffective (Jicha and Salamone, 1991; Finn et al., 1997a). A similar pattern has been reported using manipulations of the cholinergic system (Kelley et al., 1989; Salamone et al., 1990; Kikuchi de Beltran et al., 1992). Microdialysis methods demonstrated that increases in extracellular levels of ACh in VLS were correlated with the jaw movements induced by tacrine and physostigmine (Cousins et al., 1999). Cholinomimetic-induced TJMs were suppressed by local injections of muscarinic antagonists into the VLS but not into the medial striatum (Kelley et al., 1989; Salamone et al., 1990; Kikuchi de Beltran et al., 1992; Mayorga et al., 1997). Hemicholinium, which reduces ACh synthesis by blocking high affinity choline uptake, suppressed tacrine-induced jaw movements when injected into the VLS, but not into overlying cortex (Cousins et al., 1999). The suppression of pilocarpine-induced jaw movements that was produced by the DA D1 agonist SKF 82958 was reversed by injections of the D1 antagonist SCH 23390 into VLS, but not overlying cortex (Mayorga et al., 1999a). In addition, injections of the c-AMP analog 8-bromo-c-AMP into the VLS suppressed pilocarpine-induced jaw movements, while injections into cortex were ineffective (Mayorga et al., 1999b).

Most recently, it has been hypothesized that the VLS is the neostriatal subregion within which adenosine $\mathrm{A}_{2 \mathrm{~A}}$ antagonists can suppress TJM activity. Recent studies demonstrated that injections of the adenosine $\mathrm{A}_{2 \mathrm{~A}}$ antagonist MSX-3 directly into the VLS suppressed the TJMs induced by the DA antagonist pimozide

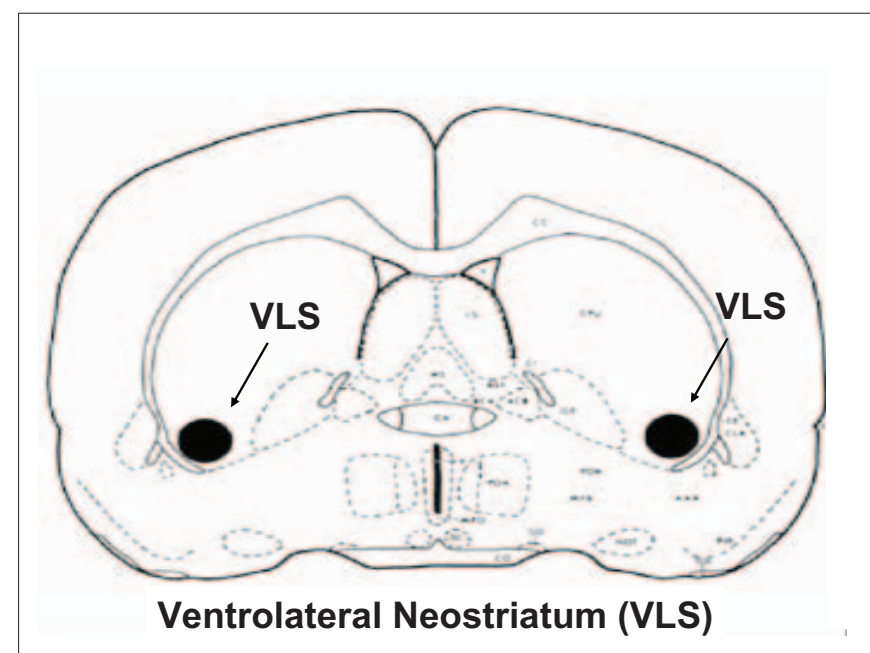

FIGURE 3 | Drawing of coronal section from rat brain, modified from Pellegrino et al. (1979) to show location of the ventrolateral neostriatum (VLS), which is a critical striatal subregion at which DA, ACh, and adenosine receptor mechanisms interact to regulate tremulous jaw movements (see text for references). 
(Salamone et al., 2008a). In addition, the adenosine $\mathrm{A}_{2 \mathrm{~A}}$ antagonist istradefylline reversed pimozide-induced $\mathrm{c}$-Fos expression in the VLS at a dose that also suppressed pimozide-induced TJMs (Betz et al., 2009).

\section{TREMULOUS JAW MOVEMENTS ARE NOT A MODEL OF TARDIVE DYSKINESIA}

Since oral movements in rats have been observed to result from chronic administration of DA antagonists, it could be suggested that TJMs represent an animal model of tardive dyskinesia (Ellison et al., 1987; Ellison and See, 1989; Creed et al., 2010). However, several lines of evidence conflict with this view. First, the fact that a tremor is orofacial does not make it a model of tardive dyskinesia, per se. As reviewed above, parkinsonian tremors can include up-and-down movements of the jaw (Barbeau, 1986; Hunker and Abbs, 1990), and "rabbit syndrome" is a drug-induced parkinsonian tremor that is characterized by chewing-like movements (Sovner and Dimascio, 1977; Weiss et al., 1980; Tarsy, 1983). Differences between rodents and humans in the relative prevalence of hand versus jaw tremor may simply be due to species differences in motor system anatomy and physiology (i.e., the relative proportion of the motor system dedicated to orofacial versus limb control in rodents and humans; Salamone et al., 1998).

By definition, tardive dyskinesia is produced by chronic administration of DA antagonists. In contrast, TJMs in rats can be produced by acute or sub-chronic administration of DA antagonists (Glassman and Glassman, 1980; Rupniak et al., 1985, 1986; Jicha and Salamone, 1991; Steinpreis and Salamone, 1993; Steinpreis et al., 1993; Egan et al., 1996; Ishiwari et al., 2005; Salamone et al., 2008a; Collins et al., 2010a; Galtieri et al., 2010) or by acute DA depletion with reserpine (Baskin and Salamone, 1993; Steinpreis and Salamone, 1993; Salamone et al., 2008b). Furthermore, while muscarinic ACh antagonists reduce both parkinsonian symptoms in humans and TJMs in rats (Betz et al., 2007; Collins et al., 2011), they worsen tardive dyskinesia (Fahn et al., 1974; Burnett et al., 1980; Noring et al., 1984). Similarly, while L-DOPA reduces TJMs (Cousins et al., 1997), it is well known to induce dyskinesias. Finally, as described earlier, the jaw movements induced by DA depletion or cholinomimetics have frequency characteristics that are quite different from tardive dyskinesia. While TJMs show maximal activity in the 3 to $7-\mathrm{Hz}$ frequency range (See and Chapman, 1991; Salamone and Baskin, 1996; Finn et al., 1997b; Mayorga et al., 1997; Cousins et al., 1998; Salamone et al., 1998; Ishiwari et al., 2005; Collins et al., 2010a; Galtieri et al., 2010), tardive dyskinesia is typically in the range of $1-2 \mathrm{~Hz}$ (Alpert et al., 1976; Wirshing et al., 1989a,b).

\section{THE UTILITY OF THE TREMULOUS JAW MOVEMENT MODEL FOR ASSESSING NOVEL TREATMENT STRATEGIES FOR TREMOR: RECENT DEVELOPMENTS}

As described above, basal ganglia regulation of motor function involves interactions between a wide array of transmitters and neuromodulators, including DA, ACh, adenosine, 5-HT, GLU, and GABA, as well as circuits that interconnect striatal and nonstriatal regions. The complexity of these interactions provides a daunting challenge to the investigator, but it also provides a framework for understanding how a symptom such as tremor can be induced or ameliorated by a variety of different conditions. Moreover, it provides avenues for the development of novel treatments for tremor.

In view of the continued uncertainty about the pathophysiology of parkinsonian tremor (Deuschl et al., 2000; Sung et al., 2008), it is important to identify the physiological conditions that are correlated with the generation of tremulous movements in animal models. As described above, pharmacological evidence links the VLS subregion of the neostriatum to the production of TJMs. In a recent preliminary study, increased tremor-related oscillatory activity in local field potential (LFP) signals was observed within the VLS subregion of the neostriatum during the occurrence of pilocarpine-induced TJMs (Collins et al., 2010c). During tremor activity, there was a sharp increase in LFP power in the VLS in the 5 to $8-\mathrm{Hz}$ band (Figure 4). This increase in power was noticeably absent in VLS when tremor activity was not occurring. This is consistent with findings from the spectral analyses of EMG traces recorded from the temporalis muscle during tremor and non-tremor epochs (see above). Furthermore, during periods of tremor activity, there was a broad increase in beta band (15-30 Hz) activity (Figure 4). This increase in beta band power was not present during periods without TJM activity. These findings are consistent with studies obtained from parkinsonian patients. Both single-unit and LFP recordings in patients with Parkinson's disease have shown evidence of tremorrelated frequencies $(\sim 4-8 \mathrm{~Hz})$ and increased "beta" $(\sim 8-30 \mathrm{~Hz})$ frequency activity in basal ganglia structures, typically globus pallidus, and STN (Hutchison et al., 1997; Weinberger et al., 2006; see also Hutchison et al., 2004 or Hammond et al., 2007 for reviews). Additionally, increases at both $\sim 6 \mathrm{~Hz}$ (tremor frequency) and $\sim 20 \mathrm{~Hz}$ (beta frequency) can be observed in LFP signals in globus pallidus and STN of Parkinson's disease patients off L-DOPA, while after L-DOPA treatment is reinstated, both the tremor and beta frequency LFPs diminish (Brown et al., 2001). The relationship between a specific neurophysiological phenomenon (e.g., altered output in specific structures and changes in the frequency of output) and particular Parkinsonian symptoms is unclear, although some evidence suggests that the low frequency increase at $4-8 \mathrm{~Hz}$ is related to tremor, while the increase in "beta" $(15-30 \mathrm{~Hz})$ interferes with the initiation and maintenance of movements (Levy et al., 2002; see however Weinberger et al., 2006). It has been proposed that the focal (spatial-limited) occurrence of gamma $(\sim 40-80 \mathrm{~Hz})$ is associated with movement initiation (Courtenmance et al., 2003; Masimore et al., 2005) and that changes in striatal neurochemistry that lead to parkinsonism transform basal ganglia circuits from participating in focal (spatially limited) gamma ensembles toward more global beta oscillations (e.g., Pessiglione et al., 2005). In light of this, the findings of increases in VLS LFP power at 4-8 Hz and in the beta band during TJMs may provide important information about the physiological mechanisms underlying tremorogenesis.

Tremulous jaw movements have also been examined in relation to hippocampal theta and epileptiform activity. Doses of the cholinergic agonist pilocarpine can induce increases in theta $(6-10 \mathrm{~Hz})$ during awake-immobility in the rat, but there was no obvious temporal relationship between theta and the presence/absence of TJMs (Collins et al., 2010c; Figure 5). In addition, although very 

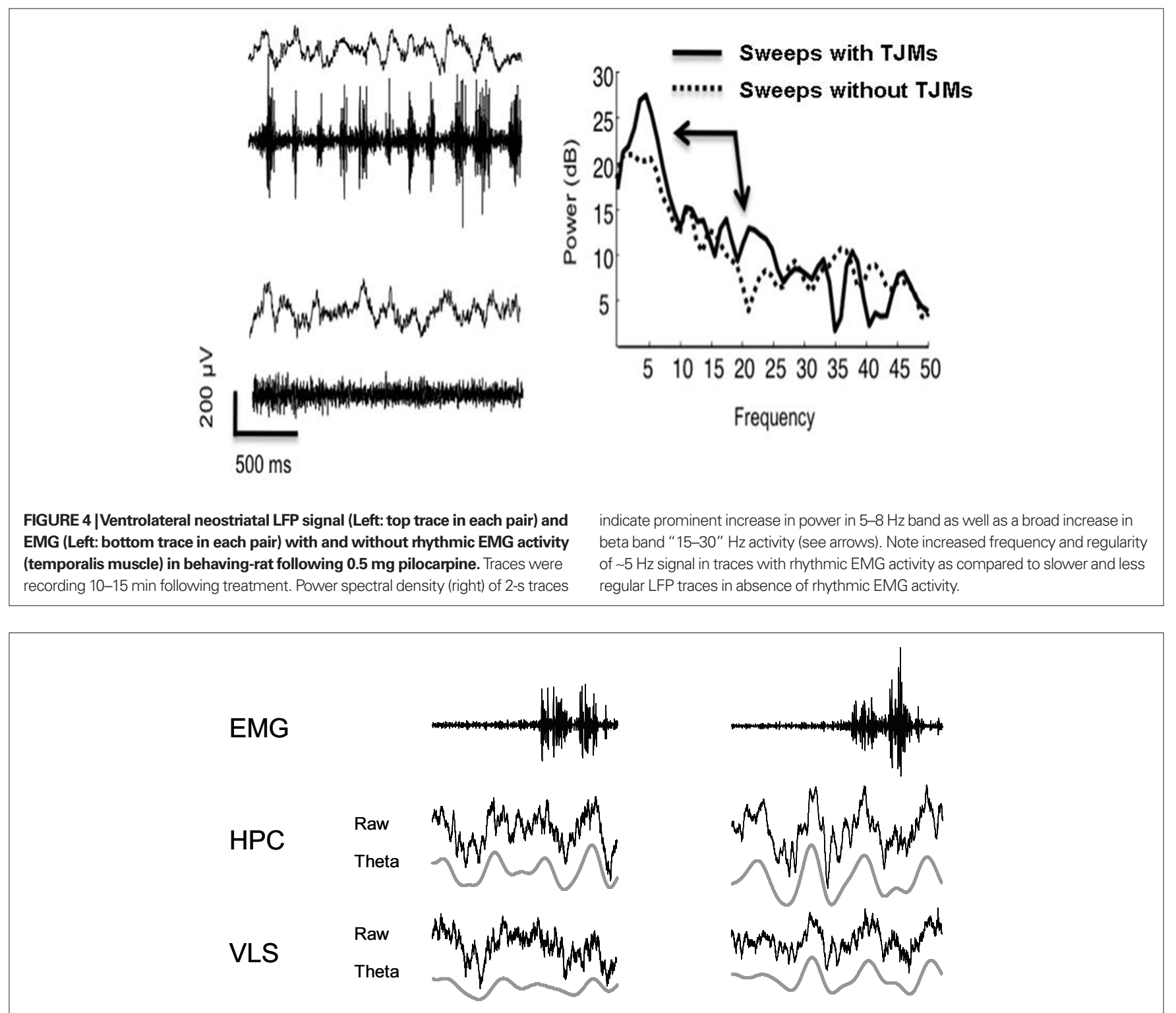

$500 \mu \mathrm{V}$

$125 \mathrm{~ms}$

FIGURE 5 | Electromyographic (EMG) activity indicates the presence of jaw movement activity (upper left trace). Concurrently recorded hippocampal LFP indicates the absence of hippocampal theta (middle left). In another trace, EMG indicates a jaw movement burst (upper right trace) occurring in the presence of hippocampal theta (middle right). The two phenomena occur independently of each other and are not correlated. Additionally, no epileptiform activity is present during the occurrence of either jaw movement burst at the dose of $0.5 \mathrm{mg} / \mathrm{kg}$ pilocarpine. Epileptiform activity only becomes apparent at a much higher dose of pilocarpine (i.e., $50 \mathrm{mg} / \mathrm{kg}$ pilocarpine, data not shown). high doses of pilocarpine such as $50.0-100 \mathrm{mg} / \mathrm{kg}$ IP can produce epileptiform activity, no epileptiform activity is seen under pharmacological conditions that produce TJMs (data not shown). In conjunction with the earlier findings presented, these recent data provide further evidence that TJMs are being induced via actions within the VLS itself and not being driven by other factors, such as hippocampal theta or epileptiform activity.
Tremulous jaw movements have become a useful model for experimental assessment of diverse tremorogenic and tremorolytic conditions. As reviewed above, adenosine $\mathrm{A}_{2 \mathrm{~A}}$ antagonists can suppress TJMs; consistent with this observation, we recently found that systemic administration of non-sedative doses of the $\mathrm{A}_{2 \mathrm{~A}}$ agonist CGS 21680 can induce TJMs (Figure 6). Moreover, TJMs have been shown to be attenuated by several serotonergic 


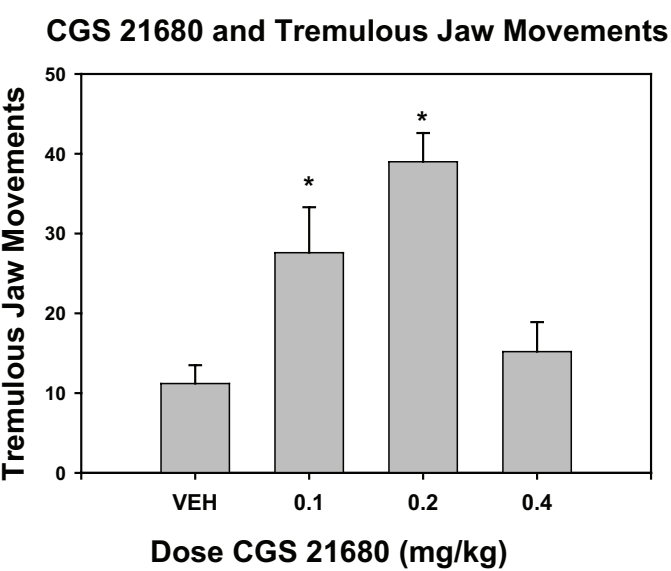

FIGURE 6 | Effect of the adenosine $A_{2 A}$ agonist CGS 21680 on the induction of tremulous jaw movements. One group of rats was used; all animals received IP injections of the following doses: saline vehicle, $0.1 \mathrm{mg} /$ $\mathrm{kg}, 0.2 \mathrm{mg} / \mathrm{kg}$, and $0.4 \mathrm{mg} / \mathrm{kg}(n=8)$. Using a within-groups design, all rats received all drug treatments in a randomly varied order (one treatment per week). Injections were given 5 min before the animals were placed in a TJM observation chamber. All animals were allowed to habituate in the chamber for 10 min, and were subsequently observed for tremulous jaw movements for $15 \mathrm{~min}$. Data are shown as mean ( \pm SEM) number of individual jaw movements (per 15 min observation period). Systemic injections of CGS 21680 induced tremulous jaw movements overall $[F(3,21)=9.15, p<0.001]$. Planned comparisons indicated that there were significant differences between vehicle and $0.1 \mathrm{mg} / \mathrm{kg}$ CGS 21680 and $0.2 \mathrm{mg} / \mathrm{kg}\left({ }^{*} p<0.05\right)$. At the $0.4-\mathrm{mg} / \mathrm{kg}$ dose of CGS 21680, rats showed profound sedation, and were either drowsy or asleep during the observation period. (Data are from the Pharm D. honors thesis of Dr. K. L. Rychalsky, University of Connecticut).

drugs, including the serotonin 5- $\mathrm{HT}_{2}$ family antagonist mianserin (Carlson et al., 2003b), the 5- $\mathrm{HT}_{2 \mathrm{~A}}$ receptor inverse agonist, ACP103 (Vanover et al., 2008), and the 5-HT(1A) agonists 8-OH-DPAT, buspirone, and F-97013-GD (Zazpe et al., 2006). The TJM model also has been incorporated into methods used to discriminate between the effects of typical antipsychotics and later-generation compounds such as clozapine, olanzapine, and quetiapine (Chesler and Salamone, 1996; Trevitt et al., 1998, 1999; Betz et al., 2005). Tacrine-induced TJMs also were shown to be suppressed by the T-type calcium channel blocker zonisamide (Miwa et al., 2008, 2009, 2011), which has anticonvulsant and tremorolytic effects in humans. Furthermore, stimulation of GABA transmission in $\mathrm{SNr}$, either by local injection the $\mathrm{GABA}_{\mathrm{A}}$ agonist muscimol (Finn et al., 1997a) or by nigral transplantation of engineered GABAproducing cells (Carlson et al., 2003a) reduced cholinomimeticinduced TJMs.

In recent years, high frequency stimulation of the STN has become a standard treatment of tremor used by neurosurgeons (Ashkan et al., 2004). In MPTP-treated primates, high frequency stimulation of the STN has been shown to improve rigidity and motor scores (Benazzouz et al., 1993, 1996; Ashkan et al., 2004). In 1993, the first bilateral STN electrodes were implanted in human patients, and high frequency STN stimulation improved rigidity, tremor, akinesia, postural/gait instabilities, independence, and quality of life, as well as reducing drug-induced dyskinesias (Benabid et al., 1994; Limousin et al., 1995, 1998; Ashkan et al.,

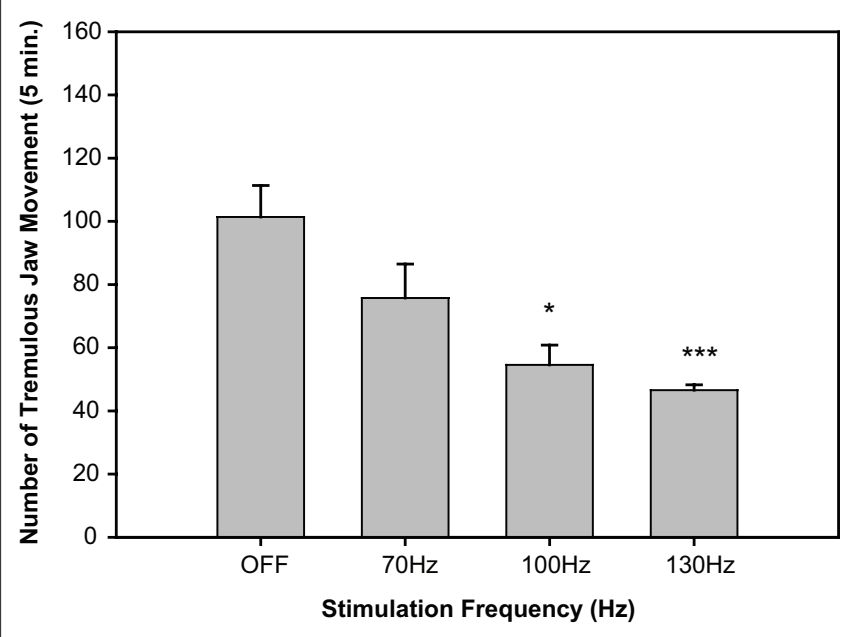

FIGURE 7 | Effect of subthalamic nucleus deep brain stimulation on the tremulous jaw movements induced by $3.0 \mathrm{mg} / \mathrm{kg}$ of the anticholinesterase galantamine (IP; data are from Collins-Praino et al., 2011a). All rats were implanted with unilateral subthalamic nucleus stimulating electrodes. After injection of galantamine, rats had alternating 5-min periods of stimulation off, followed by stimulation on; stimulation frequency was varied across the session. This curve shows the frequency-dependence of the effect of deep brain stimulation on tremulous jaw movements; there was an overall suppressive effect of brain stimulation on jaw movement activity $[F(3,50)=4.6, p<0.01] .{ }^{*} p=0.05 ;{ }^{* *} p<0.001$.

2004). Despite its efficacy as a therapeutic measure, however, a clear consensus on the mechanism of action of DBS has yet to be reached, and several competing hypotheses have been put forward. Animal models of tremor could be useful for investigating potential mechanisms of action of DBS. In a recent study by Collins-Praino et al. (2011a), TJMs were induced by a DA D1 antagonist (SCH 39166), a DA D2 antagonist (pimozide), a muscarinic agonist (pilocarpine), and an anticholinesterase (galantamine). Unilateral high frequency stimulation $(130 \mathrm{~Hz})$ of the STN, but not of a striatal control site, was shown to be effective at reversing the TJMs induced by all four pharmacological agents (Figure 7). Stimulation at lower frequencies or intensities failed to decrease TJMs compared to baseline "OFF" epochs, indicating that this response is not only dependent upon the brain area stimulated but also upon the frequency and intensity parameters used. When the adenosine $\mathrm{A}_{2 \mathrm{~A}}$ antagonist MSX-3 was co-administered with high frequency stimulation of the STN, both the frequency and intensity parameters necessary to produce a suppression of galantamine-induced TJMs were drastically reduced (Figure 7). These results serve to provide a further validation of the TJM model, and also may have critical significance for the selection of parameters used during deep brain stimulation in parkinsonian patients undergoing this procedure for the treatment of medically refractory tremor. Based on the results of this study, it is possible that the prescription of an adenosine $\mathrm{A}_{2 \mathrm{~A}}$ antagonist to these patients may result in a significant reduction in the frequency and/or intensity parameters needed for therapeutic efficacy and, thereby, a near doubling of the therapeutic window for these parkinsonian patients. 
Table 1 | Neurochemical and pharmacological conditions that induce TJMs.

\begin{tabular}{|c|c|}
\hline DA depletion using 6-OHDA & Rodriguez-Diaz et al. (2001), Jicha and Salamone (1991), Finn et al. (1997b) \\
\hline DA depletion using reserpine & Steinpreis and Salamone (1993), Baskin and Salamone (1993), Salamone and Baskin (1996), Salamone et al. (2008) \\
\hline $\begin{array}{l}\text { DA antagonism using } \\
\text { "typical" antipsychotic drugs }\end{array}$ & $\begin{array}{l}\text { Glassman and Glassman (1980), Rupniak et al. (1985, 1986), Jicha and Salamone (1991), Steinpreis et al. (1993), Steinpreis } \\
\text { and Salamone (1993), Egan et al. (1996), Trevitt et al. (1998), Wisniecki et al. (2003), Ishiwari et al. (2005), Betz et al. (2007, } \\
\text { 2009), Collins et al. (2010a) }\end{array}$ \\
\hline Muscarinic agonists & $\begin{array}{l}\text { Rupniak et al. (1983, 1985), Salamone et al. (1986, 1990), Stewart et al. (1987, 1988), Baskin et al. (1994), Finn et al. } \\
\text { (1997a,b), Collins et al. (2010a) }\end{array}$ \\
\hline
\end{tabular}

Table 2 | Antiparkinsonian drugs that reverse tremulous jaw movements.

\begin{tabular}{ll}
\hline DA Precursors (L-DOPA) & Cousins and Salamone (1996), Cousins et al. (1997) \\
DA Agonists & Baskin and Salamone (1993), Cousins et al. (1997), Mayorga et al. (1999a), Salamone et al. (2005) \\
Amantadine & Cousins et al. (1997) \\
Diphenhydramine & Carlson et al. (2000) \\
Muscarinic antagonists & Rupniak et al. (1983), Salamone et al. (1986, 1990), Steinpreis et al. (1993), Salamone and Baskin (1996), Cousins et al. (1997), \\
& Mayorga et al. (1997), Betz et al. (2007, 2009) \\
Adenosine A ${ }_{2 A}$ antagonists & Correa et al. (2004), Simola et al. (2004), Tronci et al. (2007), Salamone et al. (2008a), Betz et al. (2009), Collins et al. (2010a), \\
& Pinna et al. (2010), Collins-Praino et al. (2011b)
\end{tabular}

\section{CONCLUSION}

In conclusion, the TJM model shares many of the pharmacological, temporal, and anatomical characteristics of human parkinsonian tremor. Thus, it can be viewed as meeting a reasonable set of validation criteria as a rodent model of parkinsonian resting tremor. The validation of this model represents a significant advance forward in the scientific study of parkinsonian resting tremor, which still has a great deal of uncertainty surrounding its pathophysiology. The TJM model allows for

\section{REFERENCES}

Aarsland, D., Hutchison, M., and Larsen, J. P. (2003). Cognitive, psychiatric and motor response to galantamine in Parkinson's disease with dementia. Int. J. Geriatr. Psychiatry 18, 937-941.

Adams, R. D., and Victor M. (1993). "Tremors, myoclonus, spasms and tics," in eds R. D. Adams, and M. Victor. Principles of Neurology 5th edition (New York: McGraw Hill), 69-79.

Akai, T., Ozawa, M., Yamaguchi, M., Mizuta, E., and Kuno, S. (1995a). Combination treatment of the partial D2 agonist terguride with the D1 agonist SKF 82958 in 1-methyl4-phenyl- 1,2,3,6-tetrahydropyridine-lesioned parkinsonian cynomolgus monkeys. J. Pharmacol. Exp. Ther. 273, 309-314.

Akai, T., Ozawa, M., Yamaguchi, M., Mizuta, E., and Kuno, S. (1995b). Behavioral involvement of central dopamine D1 and D2 receptors in 1-methyl-4-phenyl-1,2,3,6-tetrahydropyridine (MPTP)-lesioned parkinsonian cynomolgus monkeys. Jpn. J. Pharmacol. 67, 117-124.

Alpert, M., Diamond, F., and Friedhoff, A. J. (1976). Tremorographic studies in tardive dyskinesia. Psychopharmacol. Bull. 12, 5-7.

Alvarez, M. V., Evidente, V. G., and DriverDunckley, E.D. (2007). Differentiating Parkinson's disease from other parkinsonian disorders. Semin. Neurol. 27, 356-362.

Aquilonius, S. M. (1980). "Cholinergic mechanisms in the CNS related to Parkinson's disease," in Parkinson's Disease-Current Progress, Problems and Management, eds U. K. Rinne, M. Klinger, and Stamm, G.(North Holland: Elsevier), 17-27.

Arai, M. (2000). Parkinsonism onset in a patient concurrently using tiapride and donepezil. Intern. Med. 39,863 .

basic research into the neurochemical mechanisms that regulate tremor, and the development of oscillatory patterns of activity in the brain that are thought to underlie tremorogenesis. Eventually, this research may lead to the development of novel treatments for tremor.

\section{ACKNOWLEDGMENT}

This work was supported by grants to John D. Salamone from the University of Connecticut Research Foundation.

Ashkan, K., Wallace, B., Bell, B. A., and Benabid, A. L. (2004). Deep brain stimulation of the subthalamic nucleus in Parkinson's Disease 1993 2003: where are we 10 years on? $\mathrm{Br}$. J. Neurosurg. 18, 19-34.

Bara-Jimenez, W., Sherzai, A., Dimitrova, T., Favit, A., Bibbiani, F., Gillespie, M., Morris, M. J., Mouradian, M. M., and Chase, T. N. (2003). Adenosine $\mathrm{A}(2 \mathrm{~A})$ receptor antagonist treatment of Parkinson's disease. Neurology 61, 293-296.

Barbeau, A. (1986). "Parkinson's disease: clinical features and etiopathology," in Handbook of Clinical Neurology, Vol. 5 Extrapyramidal Disorders, eds P. J. Vinken, G. W. Bruyn, and I. Klawans, II (North Holland: Elsevier), 87-152.

Baskin, P., Gianutsos, G., and Salamone, J. D. (1994). Repeated scopolamine injections sensitize rats to pilocarpineinduced vacuous jaw movements and enhance striatal muscarinic receptor binding. Pharmacol. Biochem. Behav. 49, 437-442.

Baskin, P., and Salamone, J. D. (1993). Vacuous jaw movements in rats induced by acute reserpine administration: interactions with different doses of apomorphine. Pharmacol. Biochem. Behav. 46, 793-797.

Benabid, A. L., Pollak, P., Gross, C., Hoffmann, D., Benazzouz, A., Gao, D. M., Laurent, A., Gentil, M., and Perret, J. (1994). Acute and long-term effects of subthalamic nucleus stimulation in Parkinson's disease. Stereotact. Funct. Neurosurg. 62, 76-84.

Benazzouz, A., Boraud, T., Feger, J., Burbaud, P., Bioulac, B., and Gross, C. (1996).Alleviation of experimental hemiparkinsonism by highfrequency stimulation of the subthalamic nucleus in primates: a comparison with L-DOPA treatment. Mov. Disord. 11, 627-632.

Benazzouz, A., Gross, C., Feger, J., Boraud, T., and Bioulac, B. (1993). Reversal of 
rigidity and improvement in motor performance by subthalamic highfrequency stimulation in MPTPtreated monkeys. Eur. J. Neurosci. 5, 382-389.

Ben-Pazi, H., Bergman, H., Goldberg, J. A., Giladi, N., Hansel, D., Reches, A., and Simon, E. S. (2001). Synchrony of rest tremor in multiple limbs in Parkinson's disease: evidence for multiple oscillators. J. Neural Transm. 108, 287-296.

Bergman, H., and Deuschl, G. (2002). Pathophysiology of Parkinson's disease: from clinical neurology to basic neuroscience and back. Mov. Disord. 17(Suppl. 3), s28-s40.

Bergman, H., Feingold, A., Nini, A., Raz, A., Slovin, H., Abeles, M., and Vaadia, E. (1998). Physiological aspects of information processing in the basal ganglia of normal and parkinsonian patients. Trends Neurosci. 21, 32-38.

Bernheimer, H., Birkmayer, W., Hornykiewicz, O., Jellinger, K., and Seitelberger, F. (1973). Brain dopamine and the syndromes of Parkinson and Huntington: clinical, morphological and neurochemical correlations. J. Neurol. Sci. 20, 415-455.

Betz, A., Ishiwari, K., Wisniecki, A., Huyn, N., and Salamone, J. D. (2005). Quetiapine (Seroquel) shows a pattern of behavioral effects similar to the atypical antipsychotics clozapine and olanzapine: studies with tremulous jaw movements in rats. Psychopharmacology (Berl.) 179, 383-392.

Betz, A. J., McLaughlin, P. J., Burgos, M., Weber, S. M., and Salamone, J. D. (2007). The muscarinic receptor antagonist tropicamide suppresses tremulous jaw movements in a rodent model of parkinsonian tremor: possible role of M4 receptors. Psychopharmacology (Berl.) 194, 347-359.

Betz, A. J., Vontell, R., Valenta, J., Worden, L., Sink, K. S., Font, L., Correa, M., Sager, T. N., and Salamone, J. D. (2009). Effects of the adenosine A2A antagonist KW-6002 (istradefylline) on pimozide-induced oral tremor and striatal c-Fos expression: comparisons with the muscarinic antagonist tropicamide. Neuroscience 163, 97-108.

Bevan, M. D., Magill, P. J., Terman, D., Bolam, J. P., and Wilson, C. J. (2002). Move to the rhythm: oscillations in the subthalamic nucleus-external globus pallidus network. Trends Neurosci. 25, 525-531.

Binder, S., Deuschl, G., and Volkmann, J. (2009). Effect of cabergoline on parkinsonian tremor assessed by long-term actigraphy. Eur. Neurol. 61, 149-153.
Bourke, D., and Drukenbrod, R. W. (1998). Possible association between donepezil and worsening Parkinson's disease. Ann. Pharmacother. 32, 610-611.

Boyce, S., Rupniak, N. M., Steventon, M. J., and Iversen, S. D. (1990). Differential effects of D1 and D2 agonists in MPTP-treated primates: functional implications for Parkinson's disease. Neurology 40, 927-933.

Braun, A., Fabbrini, G., Mouradian, M. M., Serrati, C., Barone, P., and Chase, T. (1987). Selective D-1 dopamine receptor agonist treatment of Parkinson's disease. J. Neural Transm. 68, 41-50.

Brown, P. (2003). Oscillatory nature of human basal ganglia activity: relationship to the pathophysiology of Parkinson's disease. Mov. Disord. 18, 357-363.

Brown, P., Oliviero, A., Mazzone, P., Insola, A., Tonali, P., and Di Lazzaro, V.(2001). Dopamine dependency of oscillations between subthalamic nucleus and pallidum in Parkinson's disease. J. Neurosci. 21, 1033-1038.

Burnett, G. B., Prange, A. J., Wilson, I. C., Jolli, L. A., Creese, I. C., and Snyder, S. H. (1980). Adverse effects of anticholinergic antiparkinsonian drugs in tardive dyskinesia. Neuropsychobiology 6, 109-120.

Calabresi, P., Centonze, D., Gubellini, P., Pisani, A., and Bernardi, G. (2000). Acetylcholine-mediated modulation of striatal function. Trends Neurosci. 23, 120-126.

Calabresi, P., Picconi, B., Parnetti, L., and Di Filippo, M. (2006). A convergent model for cognitive dysfunctions in Parkinson's disease: the critical dopamine-acetylcholine synaptic balance. Lancet Neurol. 5, 974-983.

Carlson, B. B., Behrstock, S., Tobin, A. J., and Salamone, J. D. (2003a). Brain implantations of engineered GABAreleasing cells suppress tremor in an animal model of parkinsonism. Neuroscience 119, 927-932.

Carlson, B. B., Wisniecki, A., and Salamone, J. D. (2003b). Local injections of the 5-hydroxytryptamine antagonist mianserin into substantia nigra pars reticulara block tremulous jaw movements in rats: studies with a putative model of parkinsonian tremor. Psychopharmacology (Berl.) 165, 229-237.

Carlson, B. B., Trevitt, J. T., and Salamone, J. D. (2000). Effects of H1 antagonists on cholinomimetic-induced tremulous jaw movements: studies of diphenhydramine, doxepin, and mepyramine. Pharmacol. Biochem. Behav. 65, 683-689.

Cenci, M.A., Whishaw, I. Q., and Schallert, T. (2002). Animal models of neuro- logical deficits: how relevant is the rat? Nat. Rev. Neurosci. 3, 574-579.

Chen, J. F., Moratalla, R., Impagnatiello, F., Grandy, D. K., Cuellar, B., Rubinstein, M., Beilstein, M. A., Hacket, E., Fink, J. S., Low, M. J., Ongini, E., and Schwarzschild, M. A. (2001). The role of the D2 dopamine receptor (D2R) in A2A adenenosine-receptor (A2aR) mediated behavioral and cellular responses as revealed by $\mathrm{A} 2 \mathrm{~A}$ and D2 receptor knockout mice. Proc. Natl. Acad. Sci. U.S.A. 98, 1970-1975.

Chesler, E., and Salamone, J. (1996). Effects of acute and repeated clozapine injections on cholinomimetic-induced vacuous jaw movements. Pharmacol. Biochem. Behav. 54, 619-624.

Close, S. P., Elliott, P. J., Hayes, A. G., and Marriott,A.S.(1990).Effects of classical and novel agents in a MPTP-induced reversible model of Parkinson's disease. Psychopharmacology (Berl.) 102, 295-300.

Collins, L. E., Galtieri, D. J., Brennum, L. T., Sager, T. N., Hockemeyer, J., Müller, C. E., Hinman, J. R., Chrobak, J. J., and Salamone, J. D. (2010a). Cholinomimetic-induced tremulous jaw movements are suppressed by the adenosine A2A antagonists MSX-3 and SCH58261, but not the adenosine A1 antagonist DPCPX: possible relevance for drug-induced parkinsonism. Pharmacol. Biochem. Behav. 94, 561-569.

Collins, L. E., Galtieri, D. J., Collins, P., Jones, S. K., Port, R. G., Paul, N. E., Hockemeyer, J., Muller, C. E., and Salamone, J. D. (2010b). Interactions between adenosine and dopamine receptor antagonists with different selectivity profiles: effects on locomotor activity. Behav. Brain Res. 211, 148-155.

Collins, L. E., Chrobak, J. J., and Salamone, J. D. (2010c). The characterization of electromyographic and EEG activity in the tremulous jaw movement model: the use of time series analysis to investigate the pathophysiology of parkinsonian resting tremor. Society for Neuroscience Annual Meeting Abstract Locator, San Diego, CA.

Collins, L. E., Paul, N. E., Abbas, S. F. Leser C. E., Galtieri, D. J., Chrobak, J. J., Baqi,Y., Muller, C. E., and Salamone J. D. (2011). Oral tremor induced by galantamine in rats: a model of the parkinsonian side effects of cholinomimetics used to treat Alzheimer's disease. Pharmacol. Biochem. Behav. 99, 414-422.

Collins-Praino, L. E., Paul, N. E. Ledgard, F., Podurgiel, S., Kovner, R., Satzer, D., McPherson, M., Rhodes, C., Hussain, N., Huber,
M., Salamone, J. D., and Senatus, P. B. (2011a). Effect of subthalamic nucleus deep brain stimulation on drug-induced tremulous jaw movements. (In preparation).

Collins-Praino, L. E., Pennarolla, A., Port, R. G., Sager, T. N., and Salamone, J. D. (2011b). The novel adenosine antagonist Lu AA47070 reverses the motor and motivational effects produced by dopamine D2 receptor blockade. (Submitted).

Correa, M., Wisniecki, A., Betz, A., Dobson, D. R., O’Neill, M. F., O’Neill, M. J., and Salamone, J. D. (2004). The adenosine A2A antagonist KF 17837 reverses the locomotor suppression and tremulous jaw movements induced by haloperidol in rats: possible relevance to parkinsonism. Behav. Brain Res. 148, 47-54.

Courtenmance, R., Fujii, N., and Graybiel, A. M. (2003). Synchronous, focally modulated beta-band oscillations characterize local field potential activity in the striatum of awake behaving monkeys. J. Neurosci. 23, 11741-11752.

Cousins, M. S., Atherton, A., and Salamone, J.D. (1998). Behavioral and electromyographic characterization of the local frequency of tacrine-induced tremulous jaw movements. Physiol. Behav. 64, 153-158.

Cousins, M. S., Carriero, D. L., and Salamone, J. D. (1997). Tremulous jaw movements induced by the acetylcholinesterase inhibitor tacrine: effects of antiparkinsonian drugs. Eur. J. Pharmacol. 322, 137-145.

Cousins, M. S., Finn, M., Trevitt, J., Carriero, D. L., Conlan, A., and Salamone, J. D. (1999). The role of ventrolateral striatal acetylcholine in the production of tacrine-induced jaw movements. Pharmacol. Biochem. Behav. 62, 439-447.

Cousins, M.S., and Salamone, J. D. (1996). Involvement of ventrolateral striatal dopamine in movement initiation and execution: a microdialysis and behavioral investigation. Neuroscience 70, 849-859.

Cragg, S. J. (2006). Meaningful silences: how dopamine listens to the Ach pause. Trends Neurosci. 29, 125-131.

Creed, M., Hamani, C., and Nobrega, J. N. (2010). Deep brain stimulation of the subthalamic or entopeduncular nucleus attenuates vacuous chewing movements in a rodent model of tardive dyskinesia. Eur. Neuropsychopharmacol. 21, 393-400.

DeLong, M. R. (1990). Primate model of movement disorders of basal ganglia origin. Trends Neurosci. 13, 281-285.

Deuschl, G., Krack, P., Lauk, M., and Timmer,J. (1996). Clinical neurophys- 
iology of tremor. J. Clin. Neurophysiol. 13, 110-121.

Deuschl, G., Raethjen, J., Baron, R., Lindemann, M., Wilms, H., and Krack, P. (2000). The pathophysiology of parkinsonian tremor: a review. J. Neurol. 247(Suppl. 5), V/33-V/48.

Deuschl, G., Raethjen, J., Lindemann, M., and Krack, P. (2001). The pathophysiology of tremor. A review. Muscle Nerve 24, 716-735.

Duvoisin, R. C. (1967). Cholinergicanticholinergic antagonism in parkinsonism. Arch. Neurol. 17, 124-136.

Egan, M. F., Hurd, Y., Ferguson, J., Bachus, S. E., Hamid, E. H., and Hyde, T. M. (1996). Pharmacological and neurochemical differences between acute and tardive vacuous chewing movements induced by haloperidol. Psychopharmacology (Berl.) 127, 337-345.

Elbe, R. J., and Koller, W. C. (1990). Tremor. Baltimore, MD: Johns Hopkins University Press.

Ellison, G., and See, R. (1989). Rats administered chronic neuroleptics develop oral movements which are similar in form to those in humans with tardive dyskinesia. Psychopharmacology (Berl.) 98, 564-566.

Ellison, G., See, R., Levin, E., and Kinney, J. (1987). Tremorous mouth movements in rats administered chronic neuroleptics. Psychopharmacology $92,122-126$

Factor, S., Mark, M. H., Watts, R., Struck, L., Mori, A., Ballerini, R., Sussman, N. M., and Istradefylline 6002-US-007 Study Group. (2010). A long-term study of istradefylline in subjects with fluctuating Parkinson's disease. Parkinsonism Relat. Disord. 16, 423-426.

Fahn, W. E., Lake, C. R., and Gerber, C. J. (1974). Cholinergic suppression of tardive dyskinesia. Psychopharmacology (Berl.) 42, 135-137.

Fernandez, H. H., Greeley, D. R., Zweig, R. M., Wojcieszek, J., Mori, A., and Sussman, N. M. (2010). Istradefylline as monotherapy for Parkinson disease: results of the 6002-US-051 trial. Parkinsonism Relat. Disord. 16, 16-20.

Ferré, S., Ciruela, F., Canals, M., Marcellino, D., Burgueno, J., Casado, V., Hillion, J., Torvinen, M., Fanelli, F., Benedetti, Pd. P., Goldberg, S. R., Bouvier, M., Fuxe, K., Agnati, L. F., Lluis, C., Franco, R., and Woods, A. (2004). Adenosine A2A-dopamine D2 receptor-receptor heteromers. Targets for neuro-psychiatric disorders. Parkinsonism Relat. Disord. 10, 265-271.

Ferré, S., Freidholm, B. B., Morelli, M., Popoli, P., and Fuxe, K. (1997).
Adenosine-dopamine receptorreceptor interactions as an integrative mechanism in the basal ganglia. Trends Neurosci. 20, 482-487.

Findley, L. J. (1988). "Tremors: differential diagnosis and pharmacology," in Parkinson's Disease and Movement Disorders, eds J. Jankovic and E. Tolosa (Baltimore: Urban and Schwarzenberg), 243-262.

Findley, L. J., and Capildeo, R. (1984). Movement Disorders: Tremor. Oxford: Oxford University Press.

Findley, L. J., and Gresty, M. A. (1981). Tremor. Br. J. Hosp. Med. 26, 16-32.

Findley, L. J., and Gresty, M. A. (1988). Head, facial, and voice tremor. $A d v$. Neurol. 49, 239-253.

Findley, L. J., Gresty, M. A., and Halmagyi, G. M. (1981). Tremor, the cogwheel phenomenon and clonus in Parkinson's disease. J. Neurol. Neurosurg. Psychiatry 44, 534-546.

Finn, M., Mayorga, A. J., Conlan, A., and Salamone, J. D. (1997a). Involvement of pallidal and nigral GABA mechanisms in the generation of tremulous jaw movements in rats. Neuroscience $80,532-544$.

Finn, M., Jassen, A., Baskin, P., and Salamone, J. D. (1997b). Tremulous characteristic of vacuous jaw movements induced by pilocarpine and ventrolateral striatal dopamine depletions. Pharmacol. Biochem. Behav. 57, 243-249.

Galtieri, D. J., Collins, L. E., Paul, N. E., and Salamone, J. D. (2010). Subchronic administration of the dopamine D1 antagonist $\mathrm{SCH}$ 39166 (ecopipam) induces parkinsonian motor impairment in a rodent model of parkinsonism: potential role of the direct pathway. Society for Neuroscience Annual Meeting Abstract Locator, San Diego, CA.

Gillespie, R. J., Bamford, S. J., Gaur, S., Jordan, A. M., Lerpiniere, J., Mansell, H. L., and Stratton, G. C. (2009). Antagonists of the human A(2A) receptor. Part 5: highly bio-available pyrimidine-4-carboxamides. Bioorg. Med. Chem. Lett. 19, 2664-2667.

Glassman, R. B., and Glassman, H. N. (1980). Oral dyskinesia in brain-damaged rats withdrawn from neuroleptics: implication for models of tardive dyskinesia. Psychopharmacology (Berl.) 69, 19-25.

Gnanalingham,K.K., Erol,D.D., Hunter,A. J., Smith, L.A., Jenner, P., and Marsden, C. D. (1995). Differential anti-parkinsonian effects of benzazepine D1 dopamine agonists with varying efficacies co-administered with quinpirole in primate and rodent models of Parkinson's disease. Psychopharmacology (Berl.) 117, 287-297.
Gurevich, T. Y., Shabtai, H., Korczyn, A. D., Simon, E. S., and Giladi, N. (2006). Effect of rivastigmine on tremor in patients with Parkinson's disease and dementia. Mov. Disord. 21, 1663-1666.

Halliday, D. M., Rosenberg, J. R., Amjad, A. M., Breeze, B., Conway, B. A., and Farmer, S. F. (1995). A framework for the analysis of mixed time series/point process data-theory and application to the study of physiological tremor single motor unit discharges, and electromyograms. Prog. Biophys. Mo. Biol. 64, 237-278.

Hammond, C., Bergman, H., and Brown, P. (2007). Pathological synchronization in Parkinson's disease: networks, models and treatments. Trend Neurosci. 30, 357-364.

Hauber, W., Nagel, J., Sauer, R., and Muller, C. E. (1998). Motor effects induced by a blockade of adenosine $\mathrm{A} 2 \mathrm{~A}$ receptors in the caudate-putamen. Neuroreport 9, 1803-1806.

Hauser, R. A., Hubble, J. P., Truong, D. D., and Istradefylline US-001 Study Group. (2003). Randomized trial of the adenosine $\mathrm{A}(2 \mathrm{~A})$ receptor antagonist istradefylline in advanced PD. Neurology 61, 297-303.

Hauser, R. A., Shulman, L. M., Trugman, J.M., Roberts, J.W., Mori, A., Ballerini, R., Sussman, N. M., and Istradefylline 6002-US-013 Study Group. (2008). Study of istradefylline in patients with Parkinson's disease on levodopa with motor fluctuations. Mov. Disord. 23 , 2177-2185.

Hersch, S. M., Gutekunst, C. A., Rees, H. D., Heilman, C. J., and Levey, A. I. (1994). Distribution of m1-m4 muscarinic receptor proteins in the rat striatum: light and electron microscopic immunocytochemistry using subtype-specific antibodies. $J$. Neurosci. 14, 3351-3363.

Hoehn, M. M., and Yahr, M. D. (1967). Parkinsonism: onset, progression, and mortality. Neurology 17, 427-442.

Hornykiewicz, O. (1972). "Dopamine and its physiological significance in brain function," in The Structure and Function of Nervous Tissue, ed. G. H. Browne (New York: Academic Press), 367-414.

Hornykiewicz, O. (1973). Dopamine in the basal ganglia. Br. Med. Bull. 29, 172-178.

Hunker, C. J., and Abbs, J. H. (1990). Uniform frequency of parkinsonian resting tremor in the lips, jaw, tongue and index finger. Mov. Disord. 5 , 71-77.

Hurtado, J. M., Lachaux, J. P., Beckley, D. J., Gray, C. M., and Sigvardt, K. A. (2000). Inter- and intralimb oscillator coupling in parkinsonian tremor. Mov. Disord. 15, 683-691.
Hurtado, J.M., Rubchinsky, L. L., Sigvardt, K. A., Wheelock, V. L., and Pappas, C. T. E. (2004). Temporal evolution of oscillations and synchrony in GPi/ muscle pairs in Parkinson's disease. J. Neurophysiol. 93, 1569-1584.

Hutchison, W. D., Dostrovsky, J. O., Walters, J. R., Courtemanche, R., Boraud, T., Goldberg, J., and Brown, P. (2004). Neuronal oscillations in the basal ganglia and movement disorders: evidence from whole animal and uman recordings. J. Neurosci. 24, 9240-9243.

Hutchison, W. D., Lozano, A. M., Tasker, R. R., Lang, A. E., and Dostrovsky, J. O. (1997). Identification and characterization of neurons with tremorfrequency activity in human globus pallidus. Exp. Brain Res. 113, 557-563.

Ishiwari, K., Betz, A., Weber, S., Felsted, J., and Salamone, J. D. (2005). Validation of the tremulous jaw movement model for assessment of the motor effects of typical and atypical antipychotics: effects of pimozide (Orap) in rats. Pharmacol. Biochem. Behav. 80, 351-362.

Ishiwari, K., Mingote, S., Correa, M., Trevitt, J. T., Carlson, B. B., and Salamone, J. D. (2004). The GABA uptake inhibitor beta-alanine reduces pilocarpine-induced tremor and increases extracellular GABA in substantia nigra pars reticulata as measured by microdialysis. J. Neurosci. Methods 140, 39-46.

Jankovic, J. (2009). Disease oriented approach to botulinum toxin use. Toxicon 54, 614-623.

Jenner, P. (2005). Istradefylline, a novel adenosine $\mathrm{A} 2 \mathrm{~A}$ receptor antagonist, for the treatment of Parkinson's disease. Expert Opin. Investig. Drugs 14, 729-738.

Jicha, G., and Salamone, J. D. (1991). Vacuous jaw movements and feeding deficits in rats with ventrolateral striatal dopamine depletions: possible model of parkinsonian symptoms. J. Neurosci. 11, 3822-3829.

Kao, K. P., Kwan, S. Y., Lin, K. P., and Chang, Y. C. (1993). Coexistence of Parkinson's disease and myasthenia gravis: a case report. Clin. Neurol. Neurosurg. 95, 137-139.

Kasture, S., Pontis, S., Pinna, A., Schintu, N., Spina, L., Longoni, R., Simola, N., Ballero, M., and Morelli, M. (2009). Assessment of symptomatic and neuroprotective efficacy of Mucuna pruriens seed extract in rodent model of Parkinson's disease. Neurotox. Res. 15, 111-122.

Kelley, A. E., Bakshi, V. P., Delfs, J. M., and Lang, C. G. (1989). Cholinergic stimulation of the ventrolateral striatum elicits mouth movements in rats: 
pharmacological and regional specificity. Psychopharmacology (Berl.) 99, 542-549.

Kikuchi de Beltran, K., Koshikawa, N., Saigusa, T., Watanabe, K., Koshida, Y., and Kobayashi, M. (1992). Cholinergic/dopaminergic interaction in the rat striatum assessed from drug-induced repetitive oral movements. Eur. J. Pharmacol. 214, 181-189.

Knebel, W., Rao, N., Uchimura, T., Mori, A., Fisher, J., Gastonguay, M. R., and Chaikin, P. (2011). Population pharmacokinetic analysis of istradefylline in healthy subjects and in patients with Parkinson's disease. J. Clin. Pharmacol. $51,40-52$.

Koller, W. C. (2002). Treatment of early Parkinson's disease. Neurology 58, S79-S86.

Koster, B., Lauk, M., Timmer, J., and Lucking, C. H. (1997). Side to side correlation of pathological tremors. Electroencephalogr. Clin. Neurophysiol. 103, 211-220.

Leventoglu, A., and Baysal, A. I. (2008). Benign tremulous Parkinson's disease. Acta Neurol. Belg. 108, 48-52.

Levy, R., Ashby, P., Hutchison, W. D., Lang, A. E., Lozano, A. M., and Dostrovsky, J. O. (2002). Dependence of subthalamic nucleus oscillation on movement and dopamine in Parkinson's disease. Brain 125, 1196-1209.

LeWitt, P. A., Guttman, M., Tetrud, J. W., Tuite, P. J., Mori, A., Chaikin, P., Sussman, N. M., and 6002-US-005 Study Group. (2008). Adenosine A2A receptor antagonist istradefylline (KW-6002) reduces "off" time in Parkinson's disease: a double-blind, randomized, multicenter clinical trial (6002-US-005). Ann. Neurol. 63, 295-302.

Limousin, P., Krack, P., Pollak, P., Benazzouz, A., Ardouin, C., Hoffnann, D., and Benabid, A. L. (1998). Electrical stimulation of the subthalamic nucleus in advanced Parkinson's disease. N. Engl. J. Med. 339, 1105-1111.

Limousin, P., Pollak, P., Benazzouz, A., Hoffmann, D., Le Bas, J. F., Broussolle, E., Perret, J. E., and Benabid, A. L. (1995). Effect of Parkinsonian signs and symptoms of bilateral subthalamic nucleus stimulation. Lancet 345, 91-95.

Litvinenko, I. V., Odinak, M. M., Mogilnaya, V. I., and Emelin, A. Y. (2008). Efficacy and safety of galantamine (reminyl) for dementia in patients with Parkinson's disease (an open controlled trial). Neurosci. Behav. Physiol. 38, 937-945.

Mansur,P.H.G., Cury, L. K.P., Andrade, A. O., Pereira, A. A., Miotto, G. A., Soares,
A. B., and Naves, E. L. (2007). A review of techniques for tremor recording and quantification. Crit. Rev. Biomed. Eng. 35, 343-362.

Marsden, C. (1984). "Origins of normal and pathological tremor," in Movement Disorders: Tremor, eds L. Findley and R. Capildeo (London: Butterworth), 37-84.

Masimore, B., Schmitzer-Torbert, N. C., Kakalios, J., and Redish, A. D. (2005). Transient striatal gamma local field potentials signal movement initiation in rats. Neuroreport 16, 2021-2024.

Mayorga, A. J., Carriero, D. L., Cousins, M. S., Gianutsos, G., and Salamone, J. D. (1997). Tremulous jaw movements produced by acute tacrine administration: possible relation to parkinsonian side effects. Pharmacol. Biochem. Behav. 56, 273-279.

Mayorga, A. J., Trevitt, J. T., Conlan, A., Ginutsos, G., and Salamone, J. D. (1999a). Striatal and nigral D1 mechanisms involved in the antiparkinsonian effects of SKF 82958 (APB): studies of tremulous jaw movements in rats. Psychopharmacology 143, 72-81.

Mayorga, A. J., Gianutsos, G., and Salamone, J. D. (1999b). Effects of striatal injections of 8-bromo-cyclicAMP on pilocarpine-induced tremulous jaw movements in rats. Brain Res. 829, 180-184.

Mayorga, A. J., Cousins, M. S. Conlan, A., Gianutsos, G., and Salamone, J. D. (1999c). Characterization of the muscarinic receptor subtype mediating pilocarpine-induced tremulous jaw movements in rats. Eur. J. Pharmacol. 364, 7-11.

McCain, K. R., Sawyer, T. S., and Spiller, H. A. (2007). Evaluation of centrally acting cholinesterase inhibitor exposures in adults. Ann. Pharmacother. 41, 1632-1637.

McEvoy, J. P. (1983). The clinical use of anticholinergic drugs as treatments for extrapyramidal side effects of neuroleptic drugs. J. Clin. Psychpharmacol. 3, 288-302.

McGeorge, A. J., and Faull, R. L. M. (1989). Organization of the projection from the cerebral cortex to the striatum in the rat. Neuroscience 29, 503-537.

McSwain, M. L., and Forman, L. M. (1995). Severe parkinsonian symptom development on combination treatment with tacrine and haloperidol. J. Clin. Psychopharmacol. 15, 284.

Milanov, I. (2001). Electromyographic differentiation of tremors. Clin. Neurophysiol. 112, 1626-1632.

Miwa, H., Hama, K., Kajimoto, Y., and Kondo, T. (2008). Effects of zonisamide on experimental tremors in rats. Parkinsonism Relat. Disord. 14, 33-36.

Miwa, H., Koh, J., Kajimoto, Y., and Kondo, T. (2011). Effects of T-type calcium channel blockers on a parkinsonian tremor model in rats. Pharmacol. Biochem. Behav. 97, 656-659.

Miwa, H., Kubo, T., Suzuki, A., and Kondo, T. (2009). Effects of zonisamide on c-Fos expression under conditions of tacrine-induced tremulous jaw movements in rats: a potential mechanism underlying its anti-parkinsonian tremor effect. Parkinsonism Relat. Disord. 15, 30-35.

Mizuno, Y., Hasegawa, K., Kondo, T., Kuno, S., and Yamamoto, M. (2010). Clinical efficacy of istradefylline (KW6002) in Parkinson's disease: a randomized, controlled study. Mov. Disord. 25, 1437-1443.

Morelli, M., Di Paolo, T., Wardas, J., Calon, F., Xiao, D., and Schwarzschild, M. A. (2007). Role of adenosine A2A receptors in parkinsonian motor impairment and L-DOPA-induced motor complications. Prog. Neurobiol. 83, 293-309.

Morelli, M., and Pinna, A. (2001). Interaction between dopamine and adenosine $\mathrm{A} 2 \mathrm{~A}$ receptors as a basis for the treatment of Parkinson's disease. Neurol. Sci. 22, 71-72.

Morris, G., Arkadir, D., Nevet, A., Vaadia, E., and Bergman, H. (2004). Coincident but distinct messages of midbrain dopamine and striatal tonically active neurons. Neuron 43 , 133-143.

Morrison, S., Kerr, G., and Silburn, P. (2008). Bilateral tremor relations in Parkinson's disease: effects of mechanical coupling and medication. Parkinsonism Relat. Disord. 14, 298-308.

Muthuraman, M., Govindan, R. B., Deuschl, G., Heute, U., and Raethjen, J. (2008). Differentiating phase shift and delay in narrow band coherent signals. Clin. Neurophysiol. 119, 1062-1070.

Navan, P., Findley, L. J., Jeffs, J. A., Pearce, R. K., and Bain, P. G. (2003). Randomized, double-blind, 3-month parallel study of the effects of pramipexole, pergolide, and placebo on parkinsonian tremor. Mov. Disord. 18, 1324-1331.

Navan, P., Findley, L. J., Undy, M. B., Pearce, R. K., and Bain, P. G. (2005). A randomly assigned double-blind cross-over study examining the relative anti-parkinsonian tremor effects of pramipexole and pergolide. Eur. J. Neurol. 12, 1-8.

Noring, U., Povlesen, U. J., Casey, D. E., and Gerlach, J. (1984). Effect of a cholinomimetic drug (RS 86) in tardive dyskinesia and drugrelated parkinsonism. Psychopharmacology 84, 569-571.

Obeso, J. A., Rodríguez-Oroz, M. C., Benitez-Temino, B., Blesa, F. J., Guridi, J., Marin, C., and Rodriguez, M. (2008). Functional organization of the basal ganglia: therapeutic implications for Parkinson's disease. Mov. Disord. 23, S548-S559.

Obeso, J. A., Rodrigquez-Oroz, M. C., Rodriguez, M., Lanciego, J. L., Artieda, J., Gonzolo, N., and Olnow, C. W. (2000). Pathophysiology of the basal ganglia in Parkinson's disease. Trends Neurosci. 23, S8-S19.

Olianas, M. C., Adem, A., Karlsson, E., and Onali, P. (1996). Rat striatal muscarinic receptors coupled to the inhibition of adenylyl cyclase activity: potent block by the selective $\mathrm{m} 4$ ligand muscarinic toxin 3 (MT3). Br. J. Pharmacol. 118, 283-238.

Olianas, M. C., and Onali, P. (1999). PD 102807, a novel muscarinic M4 receptor antagonist, discriminates between striatal and cortical muscarinic receptors coupled to cyclic AMP. Life Sci. 65, 2233-2240

O'Suilleabhain, P. E., and Matsumoto, J. Y. (1998). Time-frequency analysis of tremors. Brain 121, 2127-2134.

Ott, B. R., and Lannon, M. C. (1992). Exacerbation of Parkinsonism by tacrine. Clin. Neuropharmacol. 15, 322-325.

Pellegrino, L. J., Pellegrino, A. S., and Cushman, A. J. (1979). A Stereotaxic Atlas of the Rat Brain. New York: Plenum.

Pessiglione, M., Guehl, D., Rolland, A. S., Francios, C., Hirsch, E. C., Feger, J., and Tremblay, L. (2005). Thalamic neuronal activity in dopamine-depleted primates:evidence for a loss of functional segregation within basal ganglia circuits. J. Neurosci. 25, 1523-1531.

Pinna, A. (2009). Novel investigational adenosine A2A receptor antagonists for Parkinson's disease. Expert Opin. Investig. Drugs 18, 1619-1631.

Pinna, A., Schintu, N., Simola, N., Volpini, R., Pontis, S., Cristalli, G. and Morelli, M. (2010). A new ethyladenine antagonist of adenosine $\mathrm{A}(2 \mathrm{~A})$ receptors: behavioral and biochemical characterization as an antiparkinsonian drug. Neuropharmacology 58, 613-623.

Pisa, M. (1988). Motor somatotopy in the striatum of rat: manipulation, biting and gait. Behav. Brain Res. 27, 21-35.

Pisani, A., Bernardi, G., Ding, J., and Surmeier, D. J. (2007). Re-emergence of striatal cholinergic interneurons in movement disorders. Trends Neurosci. 30, 545-553.

Pisani, A., Bonsi, P., Centonze, D. Gubellini, P., Bernardi, G., and 
Calabresi, P. (2003). Targeting striatal cholinergic interneurons in Parkinson's disease: focus on metabotropic glutamate receptors. Neuropharmacology 45, 45-56.

Raethjen, J., Govindan, R. B., Muthuraman, M., Kopper, F., Volkmann, J., and Deuschl, G. (2009). Cortical correlates of the basic and first harmonic frequency of Parkinsonian tremor. Clin. Neurophysiol. 120, 1866-1872.

Raethjen, J., Lindemann, M., Schmaljohann, H., Wenzelburger, R., Pfister, G., and Deuschl, G. (2000). Multiple oscillators are causing parkinsonian and essential tremor. Mov Disord. 15, 84-94.

Reck, C., Florin, E., Wojtecki, L., Krause, H., Groiss, S., Voges, J., Maarouf, M., Sturm, V., Schnitzler, A., and Timmermann, L. (2009). Characterization of tremor-associated local field potentials in the subthalamic nucleus in Parkinson's disease. Eur. J. Neurosci. 29, 599-612.

Rodriguez Diaz, M., Abdala, P., BarrosoChinea, P., Obeso, J., and GonzalezHernandez, T. (2001). Motor behavioural changes after intracerebroventricular injection of 6-hydroxydopamine in the rat: an animal model of Parkinson's disease. Behav. Brain Res. 122, 79-92.

Rosin, D. L., Robeva, A., Woodard, R. L., Guyenet, P. G., and Linden, J. (1998). Immunohistochemical localization of adenosine $\mathrm{A} 2 \mathrm{~A}$ receptors in the rat central nervous system. J. Comp. Neurol. 401, 163-186.

Rupniak, N. M., Jenner, P., and Marsden, C. D. (1986). Acute dystonia induced by neuroleptic drugs. Psychopharmacology 88, 403-419.

Rupniak, N. M. J., Jenner, P., and Marsden, C. D. (1983). Cholinergic modulation of perioral behavior induced by chronic neuroleptic administration to rats. Psychopharmacology (Berl.) 79, 226-230.

Rupniak, N. M. J., Jenner, P., and Marsden, C. D. (1985). Pharmacological characterization of spontaneous or drug-induced purposeless chewing movements in rats. Psychopharmacology (Berl.) 85, 71-79.

Salamone, J. D. (2010). Preladenant, a novel adenosine $\mathrm{A}(2 \mathrm{~A})$ receptor antagonist for the potential treatment of parkinsonism and other disorders. Idrugs 13, 723-731.

Salamone, J. D., and Baskin, P. (1996). Vacuous jaw movements induced by acute reserpine and low-dose apomorphine: possible model of parkinsonian tremor. Pharmacol. Biochem. Behav. 53, 179-183.
Salamone, J. D., Betz, A. J., Ishiwari, K., Felsted, J., Madson, L., Mirante, B., Clark, K., Font, L., Korbey, S., Sager, T. N., Hockemeyer, J., and Muller, C. E. (2008a). Tremorolytic effects of adenosine A2A antagonists: implications for parkinsonism. Front. Biosci. 13, 3594-3605.

Salamone, J. D., Ishiwari, K., Betz, A. J., Farrar, A. M., Mingote, S. M., Font, L., Hockemeyer, J., Müller, C. E., and Correa, M. (2008b). Dopamine/ adenosine interactions related to locomotion and tremor in animal models: possible relevance to parkinsonism. Parkinsonism Relat.Disord. 14, S130-S134.

Salamone, J. D., Carlson, B. B., Rios, C., Lentini, E., Correa, M., Wisniecki, A., and Betz, A. (2005). Dopamine agonists suppress cholinomimeticinduced tremulous jaw movements in an animal model of Parkinsonism: tremorolytic effects of pergolide, ropinirole and CY 208-243. Behav. Brain Res. 156, 173-179.

Salamone, J. D., Correa, M., Carlson, B., Wisniecki, A., Mayorga, A., Nisenbaum, E., Nisenbaum, L., and Felder, C. (2001). Neostriatal muscarinic receptor subtypes involved in the generation of tremulous jaw movements in rodents. Implications for cholinergic involvement in parkinsonism. Life Sci. 68, 2579-2584.

Salamone, J. D., Johnson, C. J., McCullough, L. D., and Steinpreis, R. E. (1990). Lateral striatal cholinergic mechanisms involved in oral motor activities in the rat. Psychopharmacology 102, 529-534.

Salamone, J.D., Kurth, P.A., McCullough, L. D., Sokolowski, J. D., and Cousins, M. S. (1993a). The role of brain dopamine in response initiation: effects of haloperidol and regionally-specific dopamine depletions on the local rate of instrumental responding. Brain Res. $628,218-226$.

Salamone, J. D., Mahan, K., and Rogers, S. (1993b). Ventrolateral striatal dopamine depletions impair feeding and food handling in rats. Pharmacol. Biochem. Behav. 44, 605-610.

Salamone, J. D., Lalies, M. D., Channell, S. L., and Iversen, S. D. (1986). Behavioural and pharmacological characterization of the mouth movements induced by muscarinic agonists in the rat. Psychopharmacology $88,467-471$

Salamone, J. D., Mayorga, A. J., Trevitt, J. T., Cousins, M. S., Conlan, A., and Nawab, A. (1998). Tremulous jaw movements in rats: a model of parkinsonian tremor. Prog. Neurobiol. 56, 591-611.
Santiago, M. P., and Potter, L. T. (2001). Biotinylated m4-toxin demonstrates more M4 muscarinic receptor protein on direct than indirect striatal projection neurons. Brain Res. 894, 12-20.

Schneider, S.A., Edwards, M. J., Cordivari, C., Macleod, W. N., and Bhatia, K. P. (2006). Botulinum toxin A may be efficacious as treatment for jaw tremor in Parkinson's disease. Mov. Disord. 21 1722-1724.

Schrag, A., Keens, J., Warner, J., and Ropinirole Study Group. (2002). Ropinirole for the treatment of tremor in early Parkinson's disease. Eur. J. Neurol. 9, 253-257.

Schrag, A., Schelosky, L., Scholz, U., and Poewe, W. (1999). Reduction of Parkinsonian signs in patients with Parkinson's disease by dopaminergic versus anticholinergic single-dose challenges. Mov. Disord. 14, 252-255.

See, R., and Chapman, M. (1991). Cholinergic modulation of oral activity in drug-naive and chronic haloperidol-treated rats. Pharmacol. Biochem. Behav. 39, 49-54.

Selby, G. (1986). "Parkinson's disease," in Handbook of Clinical Neurology, eds P. Vinken and G. W. Bruyn (New York: Wiley), 173-211.

Shea, C., MacKnight, C., and Rockwood, K. (1998). Donepezil for treatment of dementia with Lewy bodies: a case series of nine patients. Int. Psychogerniatr. 10, 229-238.

Sheffield, J. K., and Jankovic, J. (2007). Botulinum toxin in the treatment of tremors, dystonias, sialorrhea and other symptoms associated with Parkinson's disease. Expert Rev. Neurother. 7, 637-647.

Simola, N., Fenu, S., Baraldi, P. G., Tabrizi, M.A., and Morelli, M. (2004). Blockade of adenosine $\mathrm{A} 2 \mathrm{~A}$ receptors antagonizes parkinsonian tremor in the rat tacrine model by an action on specific striatal regions. Exp. Neurol. 189, 182-188.

Song, I. U., Kim, J. S., Ryu, S. B., An, J. Y., and Lee, K. S. (2008). Donepezilinduced jaw tremor. Parkinsonism. Relat. Disord. 14, 584-585.

Sovner, R., and Dimascio, A. (1977). The effect of benztropine mesylate in the rabbit syndrome and tardive dyskinesia. Am. J. Psychiatry 134, 1301-1302.

Spieker, S., Strole, V., Sailer, A., Boose, A. and Dichgans, J. (1997). Validity of long-term electromyography in the quantification of tremor. Mov. Disord. 12, 985-991.

Stacy, M., Silver, D., Mendis, T., Sutton, J., Mori, A., Chaikin, P., and Sussman, N. M. (2008). A 12-week, placebocontrolled study (6002-US-006) of istradefylline in Parkinson disease. Neurology 70, 2233-2240.
Staude, G., Wolf, W., Ott, M., Oertel, W. H., and Dengler, R. (1995). Tremor as a factor in prolonged reaction times of parkinsonian patients. Mov. Disord. 10, 153-162.

Steinpreis, R.E., Baskin, P., and Salamone, J. D. (1993). Vacuous jaw movements induced by sub-chronic administration of haloperidol: interactions with scopolamine. Psychopharmacology 111, 99-105.

Steinpreis, R. E., and Salamone, J. D. (1993). Effects of acute haloperidol and reserpine administration on vacuous jaw movements in three different age groups of rats. Pharmacol. Biochem. Behav. 46, 405-409.

Stewart, B. R., Jenner, P., and Marsden, C. D. (1988). The pharmacological characterization of pilocarpine-induced chewing in the rat. Psychopharmacology (Berl.) 97, 228-234.

Stewart, B. R., Rose, S., Jenner, P., and Marsden, C. D. (1987). Pilocarpineinduced purposeless chewing behaviour in rats is dependent on intact central stores of 5-HT. Eur. J. Pharmacol. 142, 173-176.

Sung, Y. H., Chung, S. J., Kim, S. R., and Lee, M. C. (2008). Factors predicting response to dopaminergic treatments for resting tremor of Parkinson's disease. Mov. Disord. 23,137-140.

Tarsy, D. (1983). Neuroleptic-induced extrapyramidal reactions: classification, description and diagnosis. Clin. Neuropharmacol. 6, s9-s26.

Taylor, J. R., Lawrence, D. E., Redmond, J. D., Elsworth, J. D., Roth, R. H., Nichols, D. E., and Mailman, R. B. (1991). Dihydrexidine, a full dopamine D1 agonist, reduces MPTP-induced parkinsonism in monkeys. Eur. $J$. Pharmacol. 199, 389-392.

Threlfell, S., Clements, M. A., Khodai, T., Pienaar, I. S., Exley, R., Wess, J., and Cragg, S. J. (2010). Striatal muscarinic receptors promote activity dependence of dopamine transmission via distinct receptor subtypes on cholinergic interneurons in ventral versus dorsal striatum. J. Neurosci. 30, 3398-3408.

Timmer, J., Lauk, M., Pfleger, W., and Deuschl, G. (1998a). Cross-spectral analysis of physiological tremor and muscle activity. I. Theory and application to unsynchronized electromyogram. Biol. Cybern. 78, 349-357.

Timmer, J., Lauk, M., Pfleger, W., and Deuschl, G. (1998b). Cross-spectral analysis of physiological tremor and muscle activity. II. Application to synchronized electromyogram. Biol. Cybern. 78, 359-368.

Trevitt, J. T., Atherton, A., Aberman, J., and Salamone, J. D. (1998). Effects of subchronic administration of 
clozapine, thioridazine and haloperidol on tests related to extrapyramidal motor function in the rat. Psychopharmacology 137, 61-66.

Trevitt, J. T., Carlson, B. B., Correa, M., Keene, A., Morales, M., and Salamone, J. D. (2002). Interactions between dopamine D1 receptors and GABA mechanisms in substantia nigra pars reticulata: neurochemical and behavioral studies. Psychopharmacology (Berl.) 159,229-237.

Trevitt, J. T., Carlson, B. B., and Salamone, J. D. (1999). Behavioral assessment of atypical antipsychotics in rats: studies of the effects of olanzapine (Zyprexa). Psychopharmacology (Berl.) 145, 309-316.

Tronci, E., Simola, N., Borsini, F., Schintu, N., Frau, L., Carminati, P., and Morelli, M. (2007). Characterization of the antiparkinsonian effects of the new adenosine A2A receptor antagonist ST1535: acute and subchronic studies in rats. Eur. J. Pharmacol. 566, 94-102.

Vanover, K. E., Betz, A. J., Weber, S. M., Bibbiani, F., Kielaite, A., Weiner, D. M., Davis, R. E., Chase, T. N., and Salamone, J. D. (2008). A 5-HT2A receptor inverse agonist, ACP-103, reduces tremor in a rat model and levodopa-induced dyskinesias in a monkey model. Pharmacol. Biochem. Behav. 90, 540-544.

Weinberger, M., Mahant, N., Hutchison, W.D., Lozano, A. M., Moro, E., Hodaie,
M., Lang, A. E., and Dostrovsky, J. O. (2006). Beta oscillatory activity in the subthalamic nucleus and its relation to dopaminergic response in Parkinson's disease. J. Neurophysiol. 96, 3248-3256.

Weiss, K. J., Ciraulo, D. A., and Shader, R. I. (1980). Physostigmine test in the rabbit syndrome and tardive dyskinesia. Am. J. Psychiatry 137, 627-628.

Wichmann, T., Kliem, M. A., and DeLong, M. R. (2001). Antiparkinsonian and behavioral effects of inactivation of the substantia nigra pars reticulata in hemiparkinsonian primates. Exp. Neurol. 167, 410-424.

Willner, P. (1990)."Behavioural models in psychopharmacology," in Behavioral Models in Psychopharmacology, ed. P. Willner (Cambridge: Cambridge University Press), 3-18.

Wilms, H., Sievers, J., and Deuschl, G. (1999). Animal models of tremor. Mov. Disord. 14, 557-571.

Wirshing, W. C., Cummings, J. L., Dencker, S. J., and May, P. R. (1989a). Electromechanical characteristics of tardive dyskinesia. J. Neuropsychiatry Clin. Neurosci. 3, 10-17.

Wirshing, W. C., Friedenberg, D. L., Cummings, J. L., and Bartzokis, G. (1989b). Effects of anticholinergic agents on patients with tardive dyskinesia and concomittant drug-induced parkinsonism. J. Clin. Psychopharmacol. 9, 407-411.
Wisniecki, A., Correa, M., Arizzi, M. N. Ishiwari, K., and Salamone, J.D. (2003). Motor effects of GABA (A) antagonism in globus pallidus: studies of locomotion and tremulous jaw movements in rats. Psychopharmacology (Berl.) 170, 140-149.

Yassa, R., and Lal, S. (1986). Prevalence of the rabbit syndrome. Am. J. Psychiatry 143, 656-657.

Young, A., and Penney, J. (1993). Biochemical and functional organization of the basal ganglia, in Parkinson's Disease and Movement Disorders, eds J. Jankovic and E. Tolosa (Baltimore: Williams \& Wilkins), 1-12.

Young, R. P. (1986). “Tremor," in Disease of the Nervous System, eds A. K. Asbury, G. M. McKann, and M. I. McDonald (Philadelphia:W.B.Saunders), 435-451.

Zazpe, A., Artaiz, I., Innerárity, A., Del Olmo, E., Castro, E., Labeaga, L., Pazos, A., and Orjales, A. (2006). In vitro and in vivo characterization of F-97013-GD, a partial 5-HT1A agonist with antipsychotic- and antiparkinsonian-like properties. Neuropharmacology 51, 129-140.

Zhou, F. M., Wilson, C. J., and Dani, J. A. (2003). Muscarinic and nicotinic cholinergic mechanisms in the mesostriatal dopamine systems. Neuroscientist 9, 23-36.

Zigmond, M. J., Stricker, E. M., and Berger, T. W. (1987). "Parkinsonism: insights from animal models utilizing neurotoxic agents," in Animal Models of
Dementia, ed. J.T. Coyle (New York: John Wiley and Sons, Inc.), 1-38.

Conflict of Interest Statement: The authors declare that, except for income received from my primary employer, no financial support or compensation has been received from any individual or corporate entity over the past three years for research or professional service and there are no personal financial holdings that could be perceived as constituting a potential conflict of interest.

Received: 01 February 2011; paper pending published: 27 March 2011; accepted: 03 June 2011; published online: 04 July 2011.

Citation: Collins-Praino LE, Paul NE, Rychalsky KL, Hinman JR, Chrobak JJ, Senatus PB and Salamone JD (2011) Pharmacological and physiological characterization of the tremulous jaw movement model of parkinsonian tremor: Potential insights into the pathophysiology of tremor: potential insights into the pathophysiology of tremor. Front. Syst. Neurosci. 5:49. doi: 10.3389/fnsys.2011.00049

Copyright (c) 2011 Collins-Praino, Paul, Rychalsky, Hinman, Chrobak, Senatus and Salamone. This is an open-access article subject to a non-exclusive license between the authors and Frontiers Media SA, which permits use, distribution and reproduction in other forums, provided the original authors and source are credited and other Frontiers conditions are complied with. 